Cahiers Charlevoix

Études franco-ontariennes
Cahiers Charlevoix Études franco-ontariennes

or Crevenerix of

\title{
Aperçus comparatifs sur la démographie des communautés francophones dans l'est du Canada avant 1911
}

\section{Fernand Ouellet}

Volume 3, 1998

URI : https://id.erudit.org/iderudit/1039394ar

DOI : https://doi.org/10.7202/1039394ar

Aller au sommaire du numéro

\section{Éditeur(s)}

Société Charlevoix

Presses de l’Université d’Ottawa

ISSN

1203-4371 (imprimé)

2371-6878 (numérique)

Découvrir la revue

Citer cet article

Ouellet, F. (1998). Aperçus comparatifs sur la démographie des communautés francophones dans l'est du Canada avant 1911. Cahiers Charlevoix, 3, 87-177. https://doi.org/10.7202/1039394ar
Résumé de l'article

Fernand Ouellet analyse l'évolution des facteurs de la croissance naturelle qui ont opéré dans les populations québécoises, acadiennes et franco-ontariennes avant 1911. Comme préambule, il montre comment les différentes générations d'historiens et de démographes ont, jusqu'à tout récemment, décrit et interprété l'évolution de la nuptialité, de la natalité et de la mortalité dans ces trois grandes régions. En plus de faire ressortir la richesse relative de l'historiographie québécoise, par rapport à celles des Maritimes et de l'Ontario, sa démarche dégage une problématique d'ensemble qui repose sur l'idée que cette évolution, d'abord conditionnée par le besoin de se reproduire, de survivre et de se réaliser, fut, de tout temps, déterminée par la religion, l'ethnicité, les besoins de la famille, le rapport à la ville, les niveaux d'instruction et la socio-économie. Dans ce cadre, il examine l'émergence et la transformation de différents profils démographiques à l'intérieur de chacune de ces grandes régions, des provinces et des sous-régions, et il fait apparaître non seulement les similitudes et les parallélismes, mais, en même temps, la diversité des comportements qui eurent cours dans ces univers inégaux. 


\section{APERÇUS COMPARATIFS SUR LA DÉMOGRAPHIE DES COMMUNAUTÉS FRANCOPHONES DANS L'EST DU CANADA AVANT 1911*}

\section{Fernand Ouellet}

Département d'histoire Université York, Toronto

"Ce texte a été rédigé grâce à l'appui du programme Killam.

Cahiers Charlevoix 3, 1998, pp. 87-177. 


\section{SOMMAIRE}

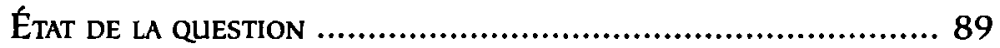

I - LA DÉMOGRAPHIE QUÉBÉCOISE .................................... 102

II - LA DÉMOGRAPHIE ACADIENNE .................................. 122

III - Ontariens et Ontariens d'origine française ................. 140

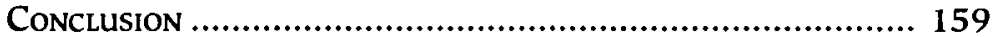




\section{ApERÇUS COMPARATIFS SUR LA DÉMOGRAPHIE DES COMMUNAUTÉS FRANCOPHONES DANS L'EST DU CANADA AVANT 1911}

\section{État de La question}

Les premiers historiens du pays avaient, à qui mieux mieux, célébré l'incomparable fécondité des races canadienne et acadienne et leur résistance sans pareille à la maladie et à la mort. Dès lors, l'image d'une population acadienne homogène doublant ses effectifs, selon Rameau de Saint-Père(1889) et Émile Lauvrière(1924), "tous les seize ans sans le concours d'aucune immigration ${ }^{1}$ " et d'une population canadienne-française du Québec tout aussi homogène, réalisant, d'après Groul $x^{2}$, la même performance en vingt ans "par la seule vertu de sa natalité», fut propagée par les historiens. Déjà, vers $1850, M^{g r}$

\footnotetext{
${ }^{1}$ Edme Rameau de Saint-Père, Une colonie féodale en Amérique, ParisMontréal, 1889, II, p. 13; Émile Lauvrière, La Tragédie d'un peuple. Histoire du peuple acadien de ses origines a nos jours, Paris, Henry Goulet, 1924, 1, p. 175s.

${ }^{2}$ Lionel Groulx, "La France d'Outre-Mer", Notre Maître, le Passé, Montréal, Granger et Frères, 1936, p. 275 ss.
} 


\section{Fernand Ouellet}

Tanguay, dans un geste de piété filiale à l'endroit de ses ancêtres canadiens-français de foi catholique, avait commencé à accumuler les données de base destinées à illustrer cet aspect de la personnalité nationale ${ }^{3}$. Puis, en 1914, Henri Bunle ajouta à cet ensemble chiffré et le traduisit en taux de nuptialité, de natalité et de mortalité qui, à son avis, démontraient l'unique vitalité passée et présente des Canadiens français. Vingt ans plus tard, Georges Langlois, bien que conscient du déclin irrémédiable de la natalité, déjà engagé à son époque, et n'y voyant d'autre solution que dans le repatriement des émigrés, abonda dans le même sens dans son Histoire de la population canadienne-française ${ }^{4}$. Aussi monta-t-il en épingle l'exceptionnelle croissance de cette population pendant plus de trois siècles, phénomène qu'il attribua non seulement aux effets apaisants de la salubrité du climat sur la mortalité mais, en plus, à l'exubérante natalité des ancêtres. À cet égard, il affirma que, de l'ancienne France à la nouvelle, les immigrants avaient spontanément "modifié leurs habitudes démographiques dans le sens de l'accélération", se multipliant alors «avec une rapidité sans exemple». Accentué au lendemain de la conquête, ce comportement collectif lui apparut même "comme un véritable défi démographique lancé au conquérant sous la forme du taux de naissance le plus élevé du monde ${ }^{5}$ \%. C'est pourquoi il avait pris à son compte des taux décennaux de natalité, oscillant entre $5,26 \%$ et $6,53 \%$, calculés par Bunle pour les années 1710 à 1770 .

${ }^{3}$ Cyprien Tanguay, $A$ travers les registres, Montréal, 1886, 276 pp.; Dictionnaire généalogique des familles canadiennes depuis la fondation de la colonie jusqu'd nos jours, Montréal, 1871, 5 vol.

4 Georges Langlois, Histoire de la population canadienne-franfaise, Montréal, Les Éditions Albert Lévesque, 1934, p. 243-248.

${ }^{5}$ Op. cit., p. 179. 
Une telle vision des choses partait du postulat erroné que, pendant des siècles, à peu près rien, dans la vie de ces sociétés, n'avait entravé l'épanouissement de la natalité et la répression de la mortalité. Bien que procédant plus scientifiquement que ses devanciers, Jacques Henripin, dans son livre La Population canadienne au XVIII ${ }^{e}$ siècle ${ }^{6}$, paru en 1954, accrédita jusqu'à un certain point cette tradition. Le taux moyen qu'il proposa pour les années 1681-1770 était de 5,70\% avec un maximum de $6,52 \%$ pendant la première décennie après 1760 : performance qu'il déclara supérieure à celle des Iraniens. Car, disait-il:

La population canadienne, prise globalement, a été l'objet d'une sélection génétique ayant opéré dans le sens d'une forte fécondité physiologique ${ }^{7}$.

Au milieu du XVIII ${ }^{e}$ siècle, rappela-t-il en 1957 , les couples qui durèrent jusqu'à ce que l'épouse ait $\mathbf{5 0}$ ans, donnèrent naissance à 8,5 ou 9 enfants en moyenne ${ }^{8}$. Comme la mortalité générale et infantile, vu l'absence de grandes épidémies et de fortes disettes, était plus basse dans la colonie qu'en France, la population doubla ses effectifs tous les trente ans en Nouvelle-France et en seulement vingt-cinq de la conquête à 1850 (la "revanche des berceaux»). Même s'il fallut, selon ses chiffres, un demi-siècle pour obtenir le même résultat par la suite, Henripin attribua ce changement à l'émigration des jeunes adultes plutôt qu'à l'avènement du contrôle volontaire des

${ }^{6}$ Jacques Henripin, La Population canadienne au début du XVIII siecle. Nuptialité, natalité et mortalité infantile, Paris, PUF, 1954, p. 39. 'Ibid., p. 88.

${ }^{8}$ Henripin, «From Acceptance of Nature to Control: the Demography of the French Canadians since the Seventeenth Century", Rioux et Martin (dir.), French-Canadian Society, Toronto, McClelland and Stewart, 1964, p. 208. 
naissances. En 1951, la fertilité des femmes canadiennesfrançaises vivant sur des fermes égalait encore, dira$\mathrm{t}$-il, celle des femmes du milieu du XVIII ${ }^{\mathrm{e}}$ siècle, alors qu'à Montréal les effets du contrôle des naissances n'étaient visibles que parmi les jeunes épouses. Ainsi, à cette date, la femme qui s'était mariée à l'âge de 15 ans, n'aurait eu que 8,7 enfants au lieu de 13 comme autrefois. Ce qui l'amena à conclure que, parmi les Canadiens français, le contrôle volontaire des naissances n'aurait débuté que vers 1925 . À cet égard, il nota que l'écart traditionnel qui avait existé entre les Canadiens français du Québec et les autres Québécois déclinait rapidement: de $38 \%$ qu'il était en 1941, à $25 \%$ en $1951^{9}$.

Ainsi, d'après Henripin écrivant en 1957, la très haute natalité des Canadiens français était plus qu'un simple événement démographique "naturel», puisque, tout considéré, elle tenait fortement à leurs croyances religieuses, à leur besoin de survie culturelle et à leur concentration dans les classes sociales à haute natalité. À vrai dire, la méfiance qu'il affiche alors à l'endroit du néomalthusianisme découlait davantage de sa vision nationaliste que de sa perspective catholique:

It is not impossible, after all, that the anti-Malthusian doctrine carried some wisdom, some part of a social perspicacity, some warning that birth-control might be used excessively if officially sponsored ${ }^{10}$.

Encore en 1968, utilisant toujours la même façon de calculer (nombre de naissances catholiques/ population au milieu de la période), il procéda à une révision de ses taux. Mais, de 1954 à 1968, il ne put

${ }^{9}$ Ibid., p. 213.

${ }^{10}$ Ibid., p. 216. 
faire mieux que de les réduire, pour la période 1681 1770 , de $5,70 \%$ à $5,60 \%$. Ses taux moyens pour les années $1760-1850$ furent de $0,97 \%$ pour la nuptialité, de $5,89 \%$ pour la natalité et de $2,95 \%$ pour la mortalité ${ }^{11}$. Pour conclure, il déclara: "Ce niveau de fécondité - certes fort élevé - n'est peut-être pas aussi exceptionnel qu'on pourrait le penser ${ }^{12}$."

Pourtant, depuis longtemps, Henripin en était conscient pour le Québec d'après 1850; on savait que les événements de toutes catégories pouvaient interférer avec la nuptialité, la natalité et la mortalité. Ainsi, depuis la fin du second conflit mondial, la théorie de la transition démographique, liant la baisse de la mortalité et de la natalité à la révolution urbaine et industrielle et aux forces de la modernisation, avait gagné du terrain à l'échelle internationale. Il va de soi que cette façon de voir les choses, qui avait aussi ses bases idéologiques, allait à l'encontre de la perspective traditionnelle qui voulait que les Canadiens français aient été exemplaires en s'abandonnant à une nature, plus généreuse que les autres, qui les incitait à engendrer le plus grand nombre possible d'enfants. Au contraire, selon la nouvelle sagesse, ils pouvaient être aussi admirables en limitant davantage leur descendance et en ressemblant le plus aux autres en cette matière.

Adoptant jusqu'à un certain point ce nouvel éclairage en 1972, Henripin reprit avec Yves Péron la route du passé. Au lieu d'utiliser la population dé-

\footnotetext{
"Sur les façons de mesurer les taux par Bunle, Langlois, Henripin et Ouellet, voir Fernand Ouellet, «L'Accroissement naturel de la population catholique québécoise avant 1850: aperçus historiographiques et quantitatifs», L'Actualité économique, vol. 59, 1983, p. 402-422.

${ }^{12}$ Henripin, Tendances et facteurs de la fécondité au Canada, Ottawa, Bureau fédéral de la statistique, 1968, p. 11.
} 
nombrée dans les recensements pour calculer leurs taux, ces démographes procédèrent à une reconstitution de la population en cumulant, année après année à partir de 1608 , les surplus des naissances sur les décès. Les taux qu'ils obtinrent, pour les années 1711-1951, étaient quinquennaux, mettant ainsi en rapport le nombre moyen de mariages, de naissances et de décès de chaque période quinquennale avec la population moyenne, catholique, canadiennefrançaise, ou totale selon le cas, de ces cinq années.

Avec les estimations nouvelles de population, l'évolution des taux devient plus plausible... Avec les nouveaux taux la hausse de la natalité dans la seconde moitié du XVIII siècle n'apparaît plus ${ }^{13}$.

En effet, d'après ces résultats, non seulement leurs taux étaient-ils inférieurs de $12,4 \%$ aux anciens, mais la nuptialité se trouvait portée à un palier plus bas à chaque période, de $0,96 \%$ en $1711-1760$, à $0,86 \%$ en 1761-1850 et à $0,78 \%$ en $1851-1883$, alors que la natalité l'était respectivement de $5,27 \%$, à $5,16 \%$ et à $4,70 \%$. Il va sans dire que la mortalité suivait ce mouvement: de $2,82 \%$ à $2,51 \%$ et à $2,27 \%$. S'interrogeant alors sur l'origine de la modernisation des comportements démographiques, Henripin et Péron la firent remonter, non plus à 1925 , mais à un moment imprécis qu'ils situèrent un peu avant ou après 1870. Car, selon eux, le nombre d'enfants par mariage, qui s'était tenu au-dessus de sept depuis 1711 , aurait commencé à baisser régulièrement entre 1865 et 1880 dans les villes et cette tendance ne se serait propagée que plus tard dans les campagnes. Henripin avait déjà fait observer par ailleurs que la fécondité

${ }^{13}$ Henripin et Yves Péron, "La Transition démographique de la province de Québec», dans Hubert Charbonneau (dir.), La Population du Québec. Etudes rétrospectives, Montréal, Boréal Express, 1973, p. 30. 
légitime avait décliné constamment au Québec après 1871, mais que, chez les Canadiens français, elle avait baissé «beaucoup plus lentement» que chez les autres Québécois, les Ontariens et même les habitants de «tous les pays industrialisés». De cette "résistance à la modernité», Henripin et Péron trouvèrent des preuves additionnelles dans le comportement de la mortalité générale et, surtout, de la mortalité infantile, toujours plus élevées parmi les Canadiens français du Québec que chez ceux d'ailleurs.

Toutefois, à cette date, comme ses collègues Charbonneau et Légaré, mais contrairement à d'autres «traumatisés par la chute récente de la natalité», Henripin, tout en étant conscient qu'un équilibre démographique «spontané» et séculaire, qui avait jusque-là assuré la survie nationale, était «en train de se rompre», ne vit pourtant pas dans la baisse substantielle de la natalité la raison principale de l'alarme nationale qu'ils sonnèrent ensemble. En effet, dirent-ils, la natalité était encore plus élevée chez les francophones parce que ceux-ci subissaient encore, plus que les autres habitants de la province, l'influence catholique, étaient moins éduqués qu'eux, moins concentrés qu'eux dans les grandes villes et plus présents qu'eux dans les classes laborieuses. À vrai dire, leur inquiétude majeure provenait du déficit migratoire francophone et de l'attrait qu'exerçait l'anglais sur les immigrants. Aussi, lancèrent-ils un appel en faveur d'un uensemble de mesures démographiques, économiques et sociales capables de donner une vigueur inédite à la francisation du Québec ${ }^{14}$ ». Deux ans plus tard, dans La Fin de la revanche des

${ }^{14}$ Charbonneau, Henripin et Légaré, «L'Avenir des francophones au Québec et à Montréal en l'absence de politiques adéquates", Charbonneau, La Population du Québec..., p. 110. 
berceaux. Qu'en pensent les Québécoises?, Henripin et Évelyne Lapierre-Adamcyk, sans doute devenus plus sensibles à la baisse ultra-rapide de la natalité pour la nation, reprirent, après avoir analysé les facteurs explicatifs de la baisse de la fécondité, cette idée d'une politique nataliste visant à «assurer le doublement de la population en 100 ans» et à «maintenir l'importance relative des francophones, au Canada et au Québec ${ }^{15}$ ". Aussi ne peut-on s'étonner qu'en 1975, dans sa préface du livre, Vie et mort de nos ancêtres..., de Hubert Charbonneau, Henripin n'ait pu faire autrement que de marquer le contraste entre la générosité vitale des ancêtres et la parcimonie reproductrice de la jeunesse des années 1970:

Ces ancêtres... ne devaient guère être des calculateurs et ils se reconnaîtraient mal dans leurs jeunes descendants, dont on se demande s'ils arriveront à la transmettre, cette vie, au moins dans la mesure où ils l'ont reçue. Que de chemin parcouru! Et comme cette envie de vivre a été rapidement écrasée par le fruit de l'évolution sociale ${ }^{16}$.

Pourtant, bien avant que la révolution urbaine et industrielle ne vînt perturber la démographie ancienne, qu'il déclare «naturelle», la socioéconomie, la géographie, la culture, les migrations et les rapports villes-campagnes avaient influé de maintes façons sur la croissance naturelle en Acadie et dans la vallée du Saint-Laurent. En 1948, Enid Charles, dans une étude fort complexe sur la fécondité des couples au Canada, avait fait ressortir, "both in respect of family size, and in respect of the rate at which it was changing ${ }^{17}$ », les différences entre les groupes ethniques,

${ }^{15}$ Henripin et Évelyne Adamcyk, La Fin de la revanche des berceaux:
qu'en pensent les Québécoises?, Montréal, PUM, 1974, p. III.
${ }^{16}$ Charbonneau, Vie et mort de nos ancêtres. Etude démographique,
Montréal, PUM, 1975, p. 15.
${ }^{17}$ Enid Charles, 1941. The Changing Size of the Family in Canada. 
les configurations religieuses, le niveau d'éducation, les régions, les classes, les villes et les campagnes. Ces disparités remontaient, disait l'auteur, à 1850.

En effet, déjà, au XVII ${ }^{e}$ siècle, tel que démontré par Gadoury, Landry et Charbonneau en 1985, les villes, avec leur diversité au plan des occupations, avaient constitué des entités géographiques, sociales et démographiques distinctes. Car les célibataires y étaient plus nombreux, l'alphabétisme plus répandu et les mariages, tant chez les hommes que chez les femmes, plus tardifs qu'en milieu rural. Aussi le nombre moyen d'enfants dans les familles complètes atteignait-il 9,6 dans les campagnes, mais se limitait à 6,8 en milieu urbain. À une mortalité générale, également plus substantielle, s'ajoutait une mortalité infantile, dont les taux étaient de 28,1 par 100 naissances en ville et de 18,5 en milieu rural ${ }^{18}$. Derrière tout cela, en plus de la religion, que d'événements incontrôlables avaient pu affecter dans un sens ou dans l'autre la spontanéité des individus!

Sans compter que de nouvelles disparités furent introduites par les immigrants britanniques à la suite des conquêtes de l'Acadie et du reste de la NouvelleFrance: d'une part, entre habitants d'origine française et ceux d'origine anglaise, et, de l'autre, entre catholiques et protestants. Ces polarisations furent d'autant plus marquées que, plus généralement, les nouveaux venus étaient plus alphabétisés et surreprésentés dans les occupations les plus lucratives, les métiers plus spécialisés, dans les régions les mieux avantagées et dans les villes. Il va sans dire

Census Monograph, Ottawa, Edmond Cloutier, 1948, p. 194.

${ }^{18}$ Lorraine Gadoury, Yves Landry et Hubert Charbonneau, "Démographie différentielle en Nouvelle-France: villes et campagnes", Revue d'histoire de l'Amérique française, vol. 38, 1985, p. 357-378. 
qu'après 1830 l'émigration des Canadiens français et, plus tard, des Acadiens vers les États-Unis, l'Ontario et l'Ouest contribua en plus à étendre l'aire où ces inégalités se reproduisirent. À ce sujet, rien ne laisse mieux soupçonner la complexité des facteurs en interaction à l'origine de ces disparités et de leur extraordinaire capacité de survie que les tableaux du recensement de 1961 sur la fécondité des groupes religieux et linguistiques au Canada. Données qui, d'ailleurs, confirment celles tirées du recensement de 1941 par Enid Charles.

Pour une meilleure compréhension de ces chiffres, notons d'abord que les femmes francophones déjà mariées, âgées de 65 ans et plus en 1961 et vivant sur des fermes, avaient eu 7,14 enfants dans les Provinces atlantiques, 8,32 au Québec, 7,27 en Ontario et 6,56 dans les Prairies. Par contre, celles qui vivaient dans les villes n'en avaient eu que 6,60, $5,90,5,33$ et 5,55 respectivement. Pour leur part, les femmes catholiques de 65 ans et plus, vivant sur des fermes, en avaient eu 6,42 dans les Provinces atlantiques, 8,23 au Québec, 5,73 en Ontario et 6,36 dans les Prairies. Mais leurs équivalentes urbaines n'en avaient eu que $5,53,5,70,4,47$ et 4,97 respectivement.

Même si, selon Marc Termote et Danielle Gauvreau, les femmes québécoises âgées de moins de $\mathbf{4 5}$ ans, dont la langue d'usage était autre que le français et l'anglais, avaient en 1980 une fécondité plus élevée que celle des francophones, les écarts traditionnels entre anglophones et francophones, bien que réduits à peu, subsistaient toujours ${ }^{19}$.

\footnotetext{
${ }^{19}$ Marc Termote et Danielle Gauvreau, La Situation démolinguistique du Québec, Québec, Conseil de la Langue française, 1988, p. 90-113.
} 
TABLEAU 1

(1) Le nombre d'enfants nés vivants en plus chez les catholiques que chez les protestants par femme déjà mariée âgée de 55 ans et plus selon le lieu de résidence en 1961; (2) le nombre d'enfants en plus chez les francophones que chez les anglophones dans les mêmes catégories

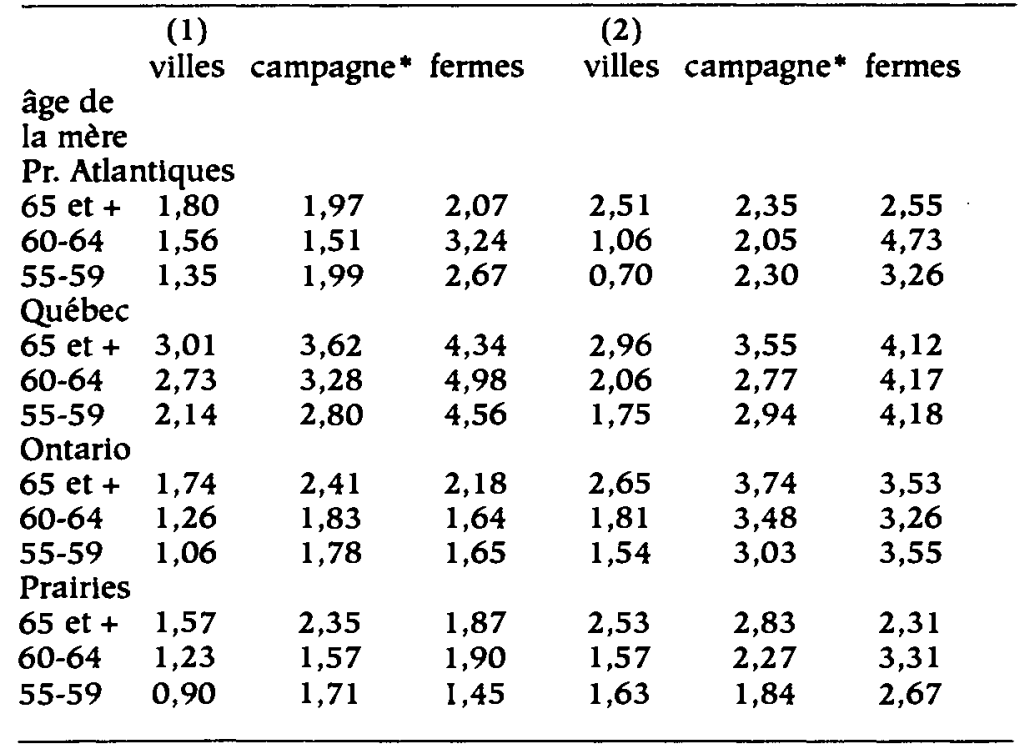

Source: Recensement du Canada, 1961, bulletin 4.1-8. ${ }^{*}$ campagne non agricole.

De telles différences avaient aussi existé au niveau de la nuptialité et de la mortalité. Dans un texte de 1961 sur L'Inégalité sociale devant la mort à Montréal, Henripin lui-même avait montré que, parmi les dix villes les plus importantes au Canada en 1951, trois d'entre elles, Québec, Montréal et Ottawa, possédaient, par une marge substantielle, les plus hauts taux de mortalité infantile. C'étaient, d'ailleurs, celles qui avaient la plus forte proportion de Canadiens français.

En 1950, à Montréal, ces écarts, autrefois plus larges, entre Français et Non-Français étaient, dit-il, 
de $40 \%$ pour la mortinatalité, de $145 \%$ pour la mortalité endogène et de $70 \%$ pour la mortalité exogène. Ayant dit cela et noté "une prédisposition" des Canadiens français à la mortalité endogène, Henripin insista néanmoins sur le fait que, sous:

le couvert d'une différence ethnique, d'autres facteurs jouent et, en particulier, le fait que chaque groupe ethnique a une structure sociale fort différente de celle des autres ${ }^{20}$.

Afin de mieux déterminer le poids relatif de la variable ethnique dans cette équation socioculturelle, il la mit en rapport avec huit variables sociales ${ }^{21}$. Pour en conclure que, si la mortalité endogène était la plus haute, là où le pourcentage des francophones était le plus élevé, la mortalité exogène était, par contre, la plus influencée par les conditions socioéconomiques. Celle-ci était donc «six fois plus forte dans les régions défavorisées» et, en général, plus lourde dans les milieux populaires que dans les classes possédantes. Même là, les Canadiens français étaient les plus vulnérables.

Rappelons que ces différences, fort anciennes, s'étendaient en plus à la mortalité générale et débordaient le cadre urbain. Ainsi, en 1891, les écarts entre catholiques et protestants, tous défavorables aux premiers, étaient de $17 \%$ dans les Maritimes, de $84 \%$ au Québec et de $31 \%$ en Ontario. Même si, dans ce cas comme dans d'autres, le facteur urbanisation était important, il n'était pas, par une marge considérable, le seul en cause. C'est ce que démontrent les

${ }^{20}$ Henripin, «L'Inégalité sociale devant la mort: la mortinatalité et la mortalité infantile à Montréal", Recherches sociographiques, vol. I, 1961, p. 3-33.

${ }^{21}$ Ibid., p. 25. Parmi les indicateurs utilisés, il y a l'instruction, le logement, les travailleurs manuels, le pourcentage des Canadiens français, les familles nombreuses et les salaires médians. 
variations de la mortalité québécoise en 1901 selon les régions, les groupes culturels et religieux, une fois mis en rapport avec les taux d'urbanisation. Notons toutefois que ces différences étaient peut-être attribuables en partie à un sous-enregistrement supérieur des décès des non-catholiques.

\section{TABLEAU 2}

Mortalité générale et urbanisation au Québec en 1901 : Canadiens français et Non-Canadiens français, catholiques et non-catholiques (taux en pourcentage)

\begin{tabular}{lcccccccc}
\hline régions & \multicolumn{2}{c}{ C. français } & \multicolumn{2}{c}{ n.-c. fr. } & \multicolumn{2}{c}{ catholiques } & \multicolumn{2}{c}{ n.-catholiques } \\
& mort. & urb. & mort. & urb. & mort. & urb. & mort. & urb. \\
Québec & 1,95 & 21,5 & 0,71 & 32,5 & 1,90 & 22,0 & 0,31 & 36,1 \\
T.-Riv. & 2,03 & 19,6 & 1,06 & 41,8 & 1,99 & 19,8 & 1,13 & 47,3 \\
Montr. & 2,30 & 51,0 & 0,67 & 64,2 & 2,13 & 52,9 & 0,71 & 61,5 \\
Prov. & 2,14 & 35,8 & 0,71 & 57,4 & 2,09 & 37,4 & 0,42 & 57,5
\end{tabular}

Sources: Recensement du Canada, 1901; F. Ouellet, «Canadiens français et Non-Francophones dans les villes québécoises et ontariennes, 1851-1911: une perspective comparative et régionale», Cotnam, Frenette et Whitfield (dir.), Ottawa, 1995, pp. 135-184.

Selon Marc Termote et Danielle Gauvreau, les francophones québécois, hommes et femmes, avaient encore, en 1980, en dépit du déclin à long terme de la mortalité, une espérance de vie, à la naissance, inférieure à celle des autres groupes linguistiques $d u$ Québec et à celle des francophones du reste du Canada. À l'intérieur du Québec, les meilleures perspectives à cet égard se trouvaient dans les régions les moins urbanisées de la province ${ }^{22}$.

Tel est le contexte changeant qui éclaire l'évolution des comportements démographiques avant 1911, au Québec d'abord, mais aussi par implication, en Acadie, au Québec et en Ontario dans leurs rapports

${ }^{22}$ Termote et Gauvreau, op. cit., p. 78-89. 
avec les composantes essentielles de la société globale dans chaque région. Pourquoi, à partir du dossier accumulé depuis 1930 et de notre propre apport, ne pas tenter de projeter une image retouchée de cette évolution complexe à l'échelle du Centre et de l'Est du Canada français?

\section{I - LA DEMographIE QUÉbécoIse}

C'est précisément parce que nous voulions déceler ces interactions, notamment les répercussions des mauvaises récoltes, des épidémies et des guerres sur les facteurs de la croissance naturelle, que nous avions, en préparant notre Histoire économique et sociale du Québec..., parue en 1966, calculé une série continue de taux annuels couvrant la période 1760-1850. Estimant alors la population de la colonie à 70000 en 1760 et ajoutant à ce chiffre, année après année, les surplus des naissances sur les décès catholiques, nous avions obtenu des taux légèrement inférieurs à ceux que Henripin et Péron devaient proposer en $1972^{23}$.

Cette série de taux annuels, nous aimerions non seulement la prolonger jusqu'en 1911, mais aussi la faire remonter à 1608. Mais, étant donné l'instabilité démographique des origines, nous avons dû limiter cette remontée dans le temps à l'année 1681. En effet, au XVII ${ }^{e}$ siècle, 14393 immigrants, parmi lesquels à peine quelques milliers de femmes, vinrent en Nouvelle-France. Ce qui, disent les auteurs de la Naissance d'une population..., obligea un grand nombre de célibataires mâles venus comme militaires et engagés

${ }^{23}$ Ouellet, "L'Accroissement naturel...", p. 418; voir aussi Histoire économique et sociale du Québec: structures et conjoncture, Montréal, Fides, 1966, p. 131, 141-143, 158, 272s. 
à retourner en France. Ce ne fut donc pas avant 1681 que l'équilibre des sexes fut, disent-ils, à peu près réalisé dans la catégorie des moins de 30 ans $^{24}$.

De cette population en voie de naître dans de telles conditions, Charbonneau et ses collaborateurs ne retinrent que ceux qui fondèrent des familles avant 1681. Ainsi, 1955 hommes et 1425 femmes, les trois cinquièmes d'entre eux étant âgés respectivement de 25 et 22 ans en moyenne et célibataires dans une proportion de $75 \%$ à leur arrivée, furent, disent-ils, à l'origine des deux tiers du patrimoine génétique de tout un peuple. Car les pionnières, âgées de 20,9 ans en moyenne à leur premier mariage et remariées dans l'année, une fois veuves, furent plus prolifiques que les Françaises de la métropole, mais moins que les Canadiennes mariées à des pionniers: une descendance complète de 7,2 enfants chez les premières et de $11,1 \mathrm{chez}$ les dernières. Comme un tiers des hommes et la moitié des femmes venaient des villes, ils furent, mais pour un temps seulement, plus urbains et alphabétisés que les Français moyens du temps.

Cette haute fécondité associée à une faible mortalité, Charbonneau et son équipe l'attribuent au «dynamisme du pays neuf», à la faible densité de la population, ainsi qu'à l'abondance de la nourriture et des terres riches.

Les pionniers forment sans doute une population sélectionnée. Les niveaux de mortalité sont trop faibles pour qu'il en soit autrement... ${ }^{25}$.

Ainsi, avant 1681, une société française de caractère

${ }^{24}$ Hubert Charbonneau, André Guillemette, Jacques Légaré, Bertrand Desjardins, Yves Landry, François Nault, Naissance d'une population. Les Français établis au Canada au XVII siècle, Montréal, PUM, 1987, p. 22.

${ }^{25}$ Charbonneau et al., ibid., p. 143. 
colonial et de tradition catholique avait commencé à se former dans la vallée du Saint-Laurent. Faute d'un nombre suffisant de femmes, elle fut pendant longtemps incapable d'absorber tous les immigrants venus dans la colonie. Le processus décrit par Charbonneau et son équipe est donc celui de l'adaptation aux conditions d'un pays neuf des $3380 \mathrm{immi-}$ grants, relativement urbanisés et alphabétisés à l'origine, qui fondèrent les premières familles. Comme la plupart d'entre eux, ainsi que leurs descendants, étaient appelés à se redistribuer peu à peu dans les campagnes, ils devinrent de moins en moins alphabétisés ${ }^{26}$ et leur comportement démographique évolua en conséquence. Tel que mentionné plus haut, les villes eurent sans doute leurs caractéristiques propres à cet égard, mais comme celles-ci devaient représenter une proportion décroissante de la population, ce furent les campagnes qui, de plus en plus, imprimèrent leur empreinte.

Entre 1663 et 1681, grâce à l'immigration, le peuplement s'était donc opéré à un rythme relativement rapide: une croissance moyenne de $4,45 \%$ par an d'un dénombrement à l'autre. Mais, entre 1681 et 1720 , le mouvement se ralentit: un taux moyen de $2,75 \%$ par an, d'un recensement à l'autre. Car, à cette époque, le solde migratoire, de positif qu'il était auparavant, devint négatif: une émigration nette de 4737 individus, qui reflétait le peu d'attrait qu'exerçait alors la colonie. Ces départs, quand même assez importants, contribuèrent à infléchir la nuptialité et

\footnotetext{
${ }^{26}$ F. Ouellet, «Fréquentation scolaire, alphabétisation et société au Québec et en Ontario jusqu'en 1911: les francophones et les autres», Cahiers Charlevoix 2, Sudbury, Société Charlevoix et Prise de parole, 1997, pp. 263-282; Economy, Class, and Nation in Quebec. Interpretive Essays, Toronto, Copp Clark Pitman, 1991, p. 126.
} 
la natalité. En effet, pendant ces quatre décennies, leur niveau respectif fluctua autour de $0,86 \%$ et de $4,77 \%$, alors que la mortalité oscilla autour de $1,93 \%$. La proportion des décès par rapport aux naissances fut alors de $52 \%$ dans les villes et de $36 \%$ dans les campagnes. Il est vrai que certaines épidémies, coïncidant ou non avec des mauvaises récoltes, furent particulièrement meurtrières, surtout en milieu urbain: dans la colonie, le taux de mortalité s'éleva soudainement à $4,10 \%$ en 1687 et, en 1703, à $5,95 \%{ }^{27}$; mais ces ponctions n'eurent pas d'effets durables sur la croissance naturelle qui resta vigoureuse (un taux de $2,82 \%$ ). En somme, une démographie qui, tout en ayant ses caractères propres, ressemblait de plus en plus, par sa sensibilité aux événements externes, à celle de la métropole.

Mais, à partir de 1720 , la conjoncture se modifia et le solde migratoire devint légèrement positif jusqu'en 1765. Il faut dire qu'avant 1740 , l'économie coloniale fut relativement prospère. Un commerce des pelleteries en expansion et des agriculteurs qui, à douze reprises, disposèrent de surplus appréciables de blé sur les marchés de l'île Royale et des Antilles $^{28}$. Tout cela incita à l'établissement des colons sur des terres, aux défrichements ainsi qu'à une nuptialité et une natalité accrues. Il est vrai que, par la suite, les paysans éprouvèrent souvent de grandes difficultés, surtout au moment des guerres. Mais, en temps de paix armée, les dépenses militaires massives procurèrent parfois plus qu'une apparence de mieuxêtre. Ces vifs contrastes se reflétèrent dans les

${ }^{27}$ Louise Dechêne, Habitants et marchands de Montréal au XVII' siècle, Montréal, Plon, 1974, p. 118 s.

${ }^{28}$ Louise Dechêne, Le Partage des subsistances au Canada sous le régime français, Montréal, Boréal, 1994, p. 21, 198, 203. 
comportements démographiques: la nuptialité s'éleva à $0,93 \%$, la natalité à $5 \%$ et la mortalité à $2,69 \%$. Partout, la mortalité absorba un pourcentage accru des naissances par rapport aux années 1681-1720, soit $25 \%$ de plus en ville et $8 \%$ à la campagne. À ce sujet, les épidémies du début des années 1730 furent mémorables, surtout celle de 1733 . En cette année de grand désastre, la mortalité supplanta partout la natalité: un indice de 144 à Montréal, de 138 à Québec, de 119 à Trois-Rivières et de 103 pour l'ensemble de la colonie. Aucun doute, épidémies, misère et guerres intervinrent, ensemble ou séparément, pour entraver l'essor de la croissance naturelle qui s'abaissa à $2,31 \%$, baisse qui, néanmoins, fut compensée par l'immigration, de sorte que la population augmenta à un taux de $2,83 \%$ par an d'un recensement à l'autre.

Comme elle l'avait fait depuis 1681 , la population catholique maintint son ascension en doublant ses effectifs tous les vingt-sept ans de 1766 à 1850 . Notons cependant que, puisque la population d'origine française ne constituait plus à cette époque toute la population catholique et que celle-ci n'égalait plus toute celle de la province, une variété croissante de profils démographiques apparut.

Vers 1765 , après la première immigration britannique, les Canadiens représentaient les neuf dixièmes de la population coloniale. Cette hégémonie diminua peu à peu jusqu'à la fin du siècle. Puis le mouvement s'intensifia au cours des décennies suivantes, en raison de l'immigration anglophone protestante et catholique venue des États-Unis et de Grande-Bretagne. En 1831, la supériorité numérique des habitants d'origine française était descendue à environ $70,6 \%$ avant 
de remonter à 75,2\% en 1844 et 1851 . L'année 1831 marqua aussi un tournant pour les catholiques d'origine britannique, puisque leur proportion parmi les catholiques s'accrut, d'une mince fraction de $1 \%$ qu'elle était en 1766 , à $5,5 \%$ en 1831 et à $10,3 \%$ en 1851 . Il est évident qu'avant 1844 , les données globales relatives à la démographie catholique reflétaient d'assez près celles des habitants d'origine française.

L'augmentation à peu près continue de la natalité de 1681 à 1850 , alors soutenue par une forte nuptialité, constitue, à notre avis, l'événement majeur de cette longue évolution à l'ère préindustrielle.

TABLEAU 3

Les facteurs de la croissance naturelle de la population catholique (1681-1911)

(en pourcentage)

\begin{tabular}{lcccc}
\hline & nuptialité & natalité & mortalité & croissance \\
$1681-1720$ & 0,86 & 4,75 & 1,93 & 2,82 \\
$1721-1765$ & 0,93 & 5,00 & 2,69 & 2,31 \\
$1766-1850$ & 0,85 & 5,14 & 2,51 & 2,63 \\
$1851-1883$ & 0,68 & 4,11 & 1,99 & 2,12 \\
$1884-1911$ & 0,61 & 3,25 & 1,75 & 1,50
\end{tabular}

Sources: Recensement du Canada, 1871, vol. 5; Robert Kuczynski, Birth Registration and Birth Statistics in Canada, Washington, The Brookings Institution, 1930, pp. 53, 59, 61; Annuaire statistique du Québec, 1916.

En vérité, cette croissance vigoureuse n'eut rien à voir avec la soi-disant "revanche des berceaux». Car elle était surtout alimentée par le déplacement progressif de la population vers les campagnes. En effet, le taux de ruralité des Canadiens s'accrut, de 65,9\% qu'il était en 1667 , à $71,5 \%$ en 1681 et à $87,7 \%$ en $1851^{29}$. Notons cependant, qu'entre 1800 et 1840 ,

${ }^{29}$ Ouellet, «Canadiens français et non-francophones dans les villes 
les pressions démographiques eurent tendance à se généraliser sur le territoire seigneurial. Aussi 41922 catholiques abandonnèrent-ils la campagne, dont 12583 allèrent vers les trois villes et le reste, sans doute des Canadiens français pour la plupart, quitta la province ${ }^{30}$.

TABLEAU 4

La population catholique (1) selon le recensement de 1831 et (2) selon les surplus cumulés des naissances sur les décès depuis 1683

(1) selon recensement

$\begin{array}{ccc}\text { pop. urbaine* }^{*} & \text { campagnes } & \text { province } \\ 45379 & 358093 & 403472 \\ 32796 & 400215 & 433011 \\ 12583 & -41922 & -29539 \\ 73,6 \% & 45,8 \% & 49,5 \%\end{array}$

Sources: pour les données sur la natalité catholique, voir recensement de 1871, vol. 5. * Trois-Rivières, Montréal et Québec.

$\mathrm{Si}$, entre 1766 et 1850 , la mortalité générale déclina légèrement, il faut aussi l'attribuer à l'influence croissante des campagnes sur les taux. En effet, par rapport aux années 1721-1765, le pourcentage des décès relativement aux naissances descendit de $0,6 \%$ en milieu rural, là où la population était la plus largement concentrée, mais s'éleva de $2,9 \%$ dans les villes. C'est d'ailleurs dans celles-ci que les épidémies (une dizaine de graves, dont certaines dignes de figurer dans la tradition orale) exercèrent le plus de ravages. Se produisant parfois en temps de guerre ou associées à de mauvaises récoltes, elles exacerbèrent partout la mortalité, mais, en particulier,

québécoises et ontariennes: 1851-1911. Une perspective comparative et régionale», Jacques Cotnam, Yves Frenette, Agnès Whitfield (dir.), La Francophonie ontarienne, Ottawa, Le Nordir, 1995, p. 138.

${ }^{30}$ Ouellet, Histoire économique et sociale du Québec, 1760-1850. Structures et conjoncture, Montréal, Fides, 1966, p. 348s. 
dans les villes. Ainsi, en 1776, le rapport des décès aux naissances fut de $163 \%$ en ville et de $64 \%$ à la campagne; en 1784 , il atteignit $142 \%$ en milieu urbain et $84 \%$ en milieu rural. Dans la ville de Québec, la mortalité infantile, dont la moyenne fut de 26,4 par 100 naissances entre 1771 et 1825 , grimpa à 39 et 43,9 respectivement à ces deux occasions. En 1832, ces pourcentages respectifs décès-naissances furent de $188 \%$ et de $59 \%^{31}$. En 1847 et 1849 , ils furent de $112 \%$ et $98 \%$ en ville et de $50 \%$ en campagne. Pour ces dix épidémies, l'indice décès-naissances s'éleva à 124 en milieu urbain et à 50 en milieu rural.

En ville, cette tension continue entre la natalité et la mortalité, accrue en temps d'épidémie, constituait un obstacle permanent à la croissance. En effet, mesurée par rapport à la population de la province au recensement de 1851, la croissance naturelle fut de seulement $1,27 \%$ en milieu urbain contre $2,83 \%$ en milieu rural. Ce qui veut dire que l'augmentation de la population urbaine ne put s'étoffer qu'en s'alimentant dans les campagnes ou à l'extérieur de la province. Après 1840 , à la suite de l'immigration anglophone catholique, de la forte croissance naturelle et du débordement de la colonisation en dehors de l'aire seigneuriale, les campagnes, aussi bien que les villes, eurent, semble-t-il, un bilan migratoire positif. De là, l'instabilité accrue des villes avec leurs populations flottantes, moussées par l'immigration, qui confèrent aux taux urbains une allure surréaliste.

Ces contrastes villes-campagnes sont d'autant plus significatifs que les premiers immigrants anglophones

${ }^{31}$ Louise Dechêne et Jean-Claude Robert, "Le Choléra dans le BasCanada: mesure des inégalités devant la mort», Hubert Charbonneau et André Larose (dir), Les Grandes Mortalités: étude méthodologique des crises démographiques du passé, Liège, 1979, p. 229-256. 
TABLEAU 5

La population catholique (1) selon le recensement de 1851 et (2) selon les surplus cumulés des naissances sur les décès depuis 1831

(1) selon le recensement

$\begin{array}{ccc}\text { Pop. urbaine* }^{*} & \text { campagne } & \text { province } \\ 79180 & 667686 & 746866 \\ 56868 & 644633 & 701501 \\ 22312 & 23053 & 45365 \\ 84 \% & 39,2 \% & 45 \%\end{array}$

Sources: pour chiffres sur les naissances et décès catholiques, voir recensement de 1871 , vol. 5. * Trois-Rivières, Montréal et Québec.

catholiques et protestants arrivés après 1760 , parmi lesquels les célibataires étaient nombreux, s'étaient regroupés surtout dans les villes. Ils étaient généralement protestants et, beaucoup plus souvent que la population en place, ils étaient alphabétisés et appartenaient à des catégories sociales moins susceptibles de haute natalité et mortalité. Vers la fin du siècle, cependant, leur recrutement se fit de plus en plus dans les classes populaires en quête de terres et d'emplois ${ }^{32}$. Ces tendances, accentuées au moment de l'immigration irlandaise catholique du début des années 1830, prirent une telle force que les Britanniques, bien que composant $48 \%$ de la population des trois villes en 1851 , étaient quand même devenus ruraux dans une proportion de $74 \%$. À cette date, le taux de ruralité des catholiques de langue anglaise était de $74,7 \%$, celui des protestants de $71,6 \%$ et celui des Canadiens d'origine française de $87,7 \%$. À ces multiples disparités, ajoutons les différences quant aux idées sur la transmission de la vie et aux pratiques prénatales et postnatales. Aussi la natalité catholique en dehors des villes de Québec et de Montréal s'établissait-elle à $4,44 \%$ en 1851 et celle des protestants

$\overline{32}$ Ouellet, Le Bas-Canada, 1791-1840. Changements structuraux et crise, Ottawa, PUO, 1976, p. 51-290. 
à 2,06\% au minimum, alors que, dans les cantons de la région de Montréal, ces niveaux étaient de 4,84\% chez les catholiques et de $3,04 \%$ chez les protestants. Notons que les Canadiens français représentaient $73 \%$ des catholiques de ces cantons. Ces inégalités se retrouvaient aussi au plan de la mortalité, surtout de la mortalité infantile ${ }^{33}$. Dans les comtés francophones en dehors de Québec et de Montréal, les taux respectifs de ces deux formes de mortalité étaient de $49 \%$ et de $132 \%$ plus élevées que dans les cantons à majorité anglophone de la province.

C'est seulement après 1851 que se produisit un déclin substantiel des taux de nuptialité, de natalité et de mortalité (tableau 3). Cette chute à long terme qui est d'environ $20 \%$ en moyenne pour chacune des trois composantes de 1851 à 1883 , peut être estimée à $10 \%$ pour la nuptialité, à $21 \%$ pour la natalité et à $12 \%$ pour la mortalité et $29 \%$ pour la croissance pendant la période qui se clôt en 1911. La croissance de la population en fut, pour longtemps, entravée, puisqu'il fallut un demi-siècle après 1851 , au lieu de vingt-sept ans comme auparavant, avant que les effectifs catholiques et canadiens-français ne doublent selon les recensements. Le taux de croissance d'un recensement à l'autre entre 1851 et 1911 fut de seulement $1,39 \%$ alors que, selon le cumul des naissances sur les décès, il fut de $1,77 \%$.

La croissance des anciennes paroisses seigneuriales, dont l'Île d'Orléans (depuis le XVII ${ }^{e}$ siècle) et la région de Lévis-Lotbinière étaient alors des exemples ${ }^{34}$, fut encore plus lente: seulement un tiers

${ }^{33}$ Recensement du Canada, 1851.

${ }^{34}$ Roch Samson et al., Histoire de Lévis-Lotbinière, Québec, IQRC, 1996, p. 276ss. 
d'augmentation en soixante ans ${ }^{35}$. Comme le dit Alain Laberge dans son étude sur l'ancien district de la Côte-du-Sud, ce qui va à l'encontre des dires de Serge Gagnon à ce sujet mais confirme ce que nous disions dans Le Bas-Canada...:

Cependant, au début du XIX siècle, il se trouve de moins en moins de seigneuries où subsiste encore l'espace disponible en quantité suffisante pour absorber les surplus de population des localités déjà saturées ${ }^{36}$.

Déjà, après 1790 , dit-il, un ralentissement substantiel de la croissance démographique s'était produit dans la Côte-du-Sud. Au lieu de doubler leurs effectifs tous les vingt-huit ans, comme auparavant, les Canadiens français de ces seigneuries ne répétèrent le même geste, de 1831 à 1921 , qu'en 41 ans dans un premier temps et en 80 dans un second. Faut-il en conclure que cette nouvelle dynamique aurait été déclenchée par une volonté bien arrêtée de contrôler les naissances et les excès de la mortalité?

À vrai dire, les couples et les individus isolés qui, après 1830, quittèrent la Côte-du-Sud pour aller prendre des terres dans le Bas-Saint-Laurent, n'étaient pas motivés de cette façon. Ils allaient, généralement poussés par la nécessité, participer à la création d'une société régionale, dont certains éléments étaient en place, à l'image de celle qu'ils avaient connue ${ }^{37}$.

${ }^{35}$ Ouellet, "La Colonisation du Saguenay-Lac-Saint-Jean... en perspective, 1850-1911. La marche des francophones dans l'Est du Canada et vers la Nouvelle-Angleterre», Saguenayensia, 36, 1994, p. 11; Yves Landry et Réal Bates, «Population et reproduction sociale à l'île d'Orléans aux XVII" et XVIII' siècles", Revue d'histoire de l'Amérique française, vol. 45, 1992 , p. 403-413.

${ }^{36}$ Alain Laberge et al., Histoire de la Côte-du-Sud, Québec, IQRC, 1993, p. 74, 81, 195; Serge Gagnon, Quebec and Its Historians. The Twentieth Century, Montreal, Harvest House, 1985, p. 126; Ouellet, Le Bas-Canada 1791-1840..., p. 222-224.

${ }^{37}$ Jean-Charles Fortin, Antonio Lechasseur et al., Histoire du Bas- 
Comme cela est habituel pendant la première étape de la colonisation, la natalité y fut même plus vigoureuse et la mortalité plus faible que dans les régions établies depuis longtemps. Une natalité moyenne de $5,26 \%$ et de mortalité de $1,72 \%$, entre 1832 et 1883 , donna lieu à une croissance énorme de 3,54\%. Même si, au fil des ans, la natalité déclina (un taux moyen de 4,42 entre 1882 et 1911) comme au Québec et que la mortalité, au contraire, augmenta (un taux moyen de 1,95\%), la croissance fut, par une marge considérable, supérieure à celle de la province (tableau 3).

La situation fut encore plus différente au Saguenay où, entre 1838 et 1911,28656 immigrants, six sur dix accompagnés de leurs familles, la plupart d'entre eux originaires de Charlevoix, allèrent s'y établir sur des terres. Une fois le premier brassage démographique révolu, ceux qui persistèrent s'employèrent à fabriquer une société à leur image en un pays neuf et isolé. Très élevée au départ, en raison de l'instabilité démographique initiale, la natalité s'y cristallisa audessus de $5 \%$ et s'y maintint jusqu'en 1930: $5,46 \%$ en moyenne de 1844 à 1883 et $5,06 \%$ de 1884 à 1911. Parmi les 6623 familles complètes analysées par Gérard Bouchard, le nombre moyen d'enfants oscilla entre 9 et 11 avant 1920 , avec un écart d'un ou deux enfants entre les cultivateurs et les autres ${ }^{38}$. La mortalité fut, au contraire, plus faible qu'au Québec, mais, comme cela s'était produit en Nouvelle-France au XVIII ${ }^{\mathrm{e}}$ siècle, elle augmenta à mesure que la société prit son parcours normal: $1,83 \%$ en moyenne

Saint-Laurent, Québec, IQRC, 1993, p. 199.

${ }^{38}$ Gérard Bouchard, Quelques arpents d'Amérique. Population, économie, famille au Saguenay, Montréal, Boréal, 1996, p. 209. 
de 1844 à 1883 et $2,06 \%$ jusqu'en $1911^{39}$, pour des taux fabuleux de croissance de $3,84 \%$ et de $3 \%$. Un peu comme si les Saguenayens avaient espéré se remettre à l'heure des pionniers de la NouvelleFrance et de leurs descendants immédiats.

Même s'il n'y eut pas brisure de tradition à la suite de la colonisation, il y eut néanmoins des différences entre les régions d'ancienne et de récente colonisation. Ces distinctions étaient attribuables, pour une large part, au degré de saturation des terroirs et, conséquemment, aux phénomènes migratoires. Ainsi, dans le Bas-Saint-Laurent, le solde migratoire fut largement positif de 1831 à 1861; puis, de là à 1911 , les départs nets s'établirent à 36790 personnes ${ }^{40}$. En Gaspésie, la population doubla en 30 ans avant 1881 et en 60 ans par la suite ${ }^{41}$, alors qu'au Saguenay, de 1851 à 1924, elle doubla successivement ses effectifs en $10,17,24$ et 22 ans.

Les mouvements de colonisation eurent donc à la fois pour effet d'accentuer la suprématie numérique des francophones dans certaines régions, de l'assurer dans celles où les anglophones avaient été majoritaires $^{42}$ et, par le fait même, de favoriser à ces endroits un épanouissement, plus ou moins durable, de leur natalité. Ce fut certainement le cas au Saguenay et dans le Bas-Saint-Laurent où, en 1911, la proportion des Canadiens français dans la population avait dépassé les 97\%. En Gaspésie, en 1901, les Britanniques, autrefois majoritaires, étaient encore assez

\footnotetext{
${ }^{39}$ Christian Pouyez, Yolande Lavoie et al., Les Saguenayens, Québec, PUL, 1983, p. 279, 299.

${ }^{40}$ Fortin, Lechasseur et al., op. cit., n. 37, voir p. 203, 371, 382.

${ }^{41}$ Jules Bélanger, Marc Desjardins et Yves Frenette, Histoire de la Gaspésie, Québec, IQRC, 1981, p. 297, 542.

${ }^{42}$ Ouellet, «La Colonisation du Saguenay-Lac-Saint-Jean...», p. 14, 16.
} 
nombreux, avec $25 \%$ de la population, pour tempérer la montée des taux provoquée par les nouveaux arrivants. Aussi l'intensité de la natalité, de la mortalité générale et infantile y était-elle inférieure à celle du Bas-Saint-Laurent par une marge se situant entre 19 et $25 \%$. Encore en 1930, Raoul Blanchard mentionna le fait que la famille moyenne canadiennefrançaise de la Gaspésie était composée de 6 à 8 enfants, alors que celle de ses voisins anglophones catholiques et protestants n'en avait que 3 ou $4^{43}$.

TABLEAU 6

Taux de natalité, de mortalité générale et de mortalité infantile dans les comtés en dehors de Québec, de Montréal et des comtés dits «anglais» des cantons de l'Est comparés à ces derniers (1861-1911)

(en pourcentage)

\begin{tabular}{rrcc}
\hline Natalité & Mortalité & $\begin{array}{c}\text { Mortalité } \\
\text { infantile }\end{array}$ \\
1851 & 135 & 201 & 207 \\
1861 & 111 & 165 & 206 \\
1871 & 103 & 135 & 180 \\
1881 & 122 & 147 & 167 \\
1891 & & 148 & 142 \\
1901 & 130 & 161 & 197 \\
1913 & 147 & 181 & \\
\hline
\end{tabular}

Sources: Recensements du Canada.

Dans les cantons de l'Est, où les Canadiens français étaient devenus largement majoritaires en 1911 , ces disparités subsistaient.

Tous ces exemples démontrent que le processus de la colonisation, bien que nécessitant des adaptations, n'impliquait ni une rupture de tradition ni, en milieu hétérogène, une uniformisation des pratiques

43 Raoul Blanchard, L'Est du Canada français. Province de Québec, Montréal, Beauchemin, 1935, t. I, p. 62s. 
culturelles. Ce sont des questions que John Little a posées à propos de deux communautés de même dimension au départ, formées entre 1848 et 1881 , dans le canton de Winslow, comté de Compton: l'une canadienne-française, appelée à durer, et l'autre écossaise, qui, après avoir peiné pendant plus d'un demisiècle sur un terroir également ingrat, quitta les lieux après 1900 . Selon ses chiffres, la fertilité des femmes canadiennes-françaises âgées de 15-49 ans y était, entre 1850 et 1880 , substantiellement plus élevée que celle des Écossaises. Non seulement se mariaientelles plus jeunes que les secondes mais, chez elles, les intervalles entre les naissances étaient de sept mois plus courts que chez les autres. «Scots couples deliberately, dit-il, began to limit the size of their families ${ }^{44}$." Cette suprématie francophone s'étendait en plus à la mortalité générale et infantile: un rapport de 158 et de 170 pour les deux formes de mortalitét ${ }^{45}$.

La baisse des trois composantes majeures de la croissance naturelle catholique à l'échelle de la province n'est done pas un fruit de la colonisation. Elle s'explique mieux, du moins en partie, par référence au mouvement d'urbanisation, d'industrialisation et d'alphabétisation dont la marche s'esquisse vers 1850. En effet, de 1850 à 1911 , la croissance annuelle moyenne de la population des villes et villages de 1000 habitants et plus s'élève à $3,83 \%$, alors que celle des campagnes descend à $0,78 \%$. Le taux d'urbanisation de la province passe alors de $15,1 \%$ à $43,2 \%$ : celui des Canadiens français augmentant de $11,5 \%$ à $39,5 \%$ et celui des autres de $25,8 \%$ à $57 \%$.

${ }_{44}$ J.I. Little, Crofters and Habitants. Settler Society, Economy, and Culture in a Quebec Township, 1848-1881, Montreal- Kingston, McGillQueen's University Press, 1991, p. 81-83.

${ }^{45}$ Ibid., p. 85-87. 
Ce mouvement devient, à vrai dire, fortement régionalisé. Ainsi, en 1851, les districts de Québec et de Montréal étaient également urbanisés, $12,4 \%$ et $12,5 \%$ respectivement, mais, en 1911, celui de Montréal l'était 2,36 fois plus. Il va de soi que ces événements appelaient un transfert continuel des hommes et des femmes vers des catégories socioprofessionnelles moins soumises aux impératifs de la reproduction familiale stimulée par la religion et la culture paysanne.

Cela ne veut pas dire qu'une fois arrivés pour de bon en ville, surtout à Québec et à Montréal, les ruraux modifièrent soudainement leurs attitudes ${ }^{46}$. Pour eux, jusqu'au jour où les nouvelles nécessités l'emportèrent et contribuèrent à un bris avec la tradition, la natalité resta ce qu'elle était auparavant. Pour parler de contrôle volontaire des naissances avant 1911, il faut se référer plus spécifiquement aux populations anglophones et, dans le cas des francophones, à des individus habitant des villes comme Montréal et Québec, plutôt que des agglomérations de petite dimension et, plus généralement, à des personnes appartenant à certaines catégories sociales plus instruites plutôt qu'à la masse.

Le fait est que la baisse échelonnée de la natalité catholique fut surtout attribuable à la chute de la nuptialité occasionnée, comme le démontrent Henripin et Péron ${ }^{47}$, par l'exode de jeunes couples et d'individus, venus de terroirs saturés et en âge de se marier, vers les villes et l'extérieur de la province. Nos chiffres, bien que moins spectaculaires que ceux de

${ }^{46}$ Lucia Ferretti, Entre voisins. La société paroissiale en milieu urbain. Saint-Pierre-Apôtre de Montréal, 1848-1930, Montréal, Boréal, 1992, 264 p.

${ }^{47}$ Henripin et Péron, «La Transition démographique de la province de Québec", op. cit., p. 37s. 
TABLEAU 7

Le population catholique (1) selon le recensement de 1881 et (2) selon le surplus cumulé des naissances sur les décès depuis le recensement de 1851

\begin{tabular}{lccc}
\hline & pop. urbaine* & campagnes & province \\
(1) selon le recensement & 168435 & 1002283 & 1170718 \\
(2) selon le cumul & 125930 & 1308744 & 1434674 \\
solde (2-1) & 42505 & -306461 & -263956 \\
décès/naissances & $75,7 \%$ & $51,7 \%$ & $56,1 \%$
\end{tabular}

Sources: pour les chiffres sur les naissances et les décès catholiques, Recensement du Canada, 1871, vol. 5. * Trois-Rivières, Québec, Montréal.

Yolande Lavoie et de Gilles Paquet, sont quand même impressionnants: 306461 personnes d'allégeance catholique, dont 42505 allèrent vers les trois villes, quittèrent les campagnes au cours des années 18511881. Pendant les trois décennies suivantes, les départs nets vers l'extérieur, bien que minimes de 1901 à 1911, furent quand même considérables dans l'ensemble: 246834 . Ces déplacements furent encore plus massifs que ces chiffres nets ne l'indiquent, puisque, d'après ce que Ramirez en dit à propos des migrants de Berthier, les retours au pays représentaient une proportion considérable des départs ${ }^{48}$.

Donc, à la suite de ces ponctions répétées, une nuptialité et une natalité en baisse et une mortalité, dont les reculs furent relativement modestes, affectèrent substantiellement la croissance: entre le niveau des années 1766-1850 et celui des années 1884-1911, le recul fut de $28 \%$ pour la nuptialité, de $37 \%$ pour la natalité, de $30 \%$ pour la mortalité et de $43 \%$ pour la croissance.

\footnotetext{
${ }^{48}$ Bruno Ramirez, Par monts et par vaux. Migrants canadiens-français et italiens dans l'économie nord-atlantique, 1860-1914, Montréal, Boréal, 1991, p. 23, 42, 123, 149.
} 
La mortalité joua donc un rôle significatif dans cette équation. De 1851 à 1881 , le rapport décès/ naissances diminua de $3,8 \%$ par rapport aux années 1765-1850 dans les trois villes mais augmenta de $8,7 \%$ dans les campagnes, pour un rapport de $75,7 \%$ en milieu urbain et de $51,7 \%$ en milieu rural. Il va de soi que les épidémies qui, le plus souvent, témoignaient de la plus grande vulnérabilité des classes populaires, des enfants, des personnes âgées et des Canadiens français à ce genre d'événements, visitèrent périodiquement la province comme autrefois. Celle de 1854 vit le rapport décès/naissances se hisser à 102 en ville et à 53 à la campagne. À Montréal, en particulier, la situation fut particulièrement difficile entre 1868 et 1874 : en 1872 et en 1874,106 et 124 décès respectivement contre 100 naissances; à la campagne, 56 et 58. L'épidémie de variole de 1885 fut, par une marge considérable, moins meurtrière que l'épidémie de choléra de 1832, que Louise Dechêne et Jean-Claude Robert décrivent comme «une attaque plus violente que toutes celles qui ont marqué la marche de l'infection à travers l'Europe ${ }^{49}$ '. En effet, à elle seule, la mortalité épidémique avait alors fauché $9,7 \%$ de la population de Québec et $7,4 \%$ de celle de Montréal. Pourtant, en 1885, la variole, en ne tuant que $1,7 \%$ de la population de Montréal, sema tout autant la panique et suscita, en plus, une émeute populaire contre la vaccination. Le nombre total des mortalités varioliques, à peine supérieur à ce qu'il avait été en 1832, affecta 3,08\% des Canadiens français mais seulement $0,60 \%$ des autres catholiques et $0,21 \%$ des protestants. Les victimes âgées de moins de dix ans représentaient $88 \%$ des pertes

\footnotetext{
${ }^{49}$ Dechêne et Robert, "Le Choléra de 1832 dans le Bas-Canada...", op. cit., p. 234.
} 
chez les premiers, $67 \%$ chez les seconds et $53 \%$ parmi les autres ${ }^{50}$.

De tels écarts ne sont pas tout à fait étonnants puisque la vulnérabilité différentielle des groupes ethniques et religieux à la maladie et à la mort s'explique par l'ensemble des circonstances économiques, socioculturelles et politiques de leur enracinement dans le milieu. À cet égard, la tuberculose, comme bien d'autres maladies mais plus encore que les épidémies, événements intermittents qu'on imputa à des agents extérieurs et qu'on voulut conjurer par des processions et des prières, interpellait sans excuses les conditions sociales au jour le jour. Non seulement affectait-elle davantage les villes que les campagnes, un coefficient de 198 pour 100000 habitants contre 163, mais elle frappait inégalement les groupes ethniques et sociaux. Encore là, les Canadiens français, avec un taux de 201 par 100000 de population, étaient plus vulnérables que les anglophones dont le taux était de 149. Notons toutefois qu'avec le temps et des améliorations dans les conditions sanitaires, scientifiques et socioéconomiques, l'incidence de la tuberculose et des maladies contagieuses diminua: une baisse de 300 par 100000 habitants en 1880 à 180 en $1914^{51}$. Curieusement, Ronald Rudin attribue la situation avantageuse des anglophones en ce domaine, phénomène qui, pourtant, datait de loin dans le passé, à la fondation, en 1909, du Royal Edward Chest Hospital:

C'est sans doute parce que cet hôpital, qui traitait des problèmes des voies respiratoires, fonctionnait en anglais

\footnotetext{
${ }^{50}$ Michæl Bliss, Plague. A Story of Smallpox in Montreal, Toronto, Harper Collins Publishers, 1991, p. 276s.

${ }^{51} \mathrm{M}$. Tétrault, «Les Maladies de la misère. Aspects de la santé publique à Montréal, 1880-1914", IQRC, vol. 36, 1983, p. 515s.
} 
que le taux de tuberculose était généralement moins élevé chez les Montréalais de langue anglaise que chez les francophones ${ }^{52}$.

Normalement, les non-francophones auraient dû être davantage touchés par ces incidences que les Canadiens français. En effet, après 1850 , leur degré de concentration dans le district de Montréal, le plus urbanisé de la province, et dans la ville de Montréal, renommée en Amérique pour sa haute mortalité, s'éloigna de plus en plus de celui des Canadiens français: $12 \%$ de plus en 1851 et $33 \%$ en 1911 . Leur taux d'urbanisation dans la région s'accrut de $27 \%$ à $63 \%$ pendant que celui des Canadiens français montait de $12 \%$ à $55 \%$. Notons, cependant, qu'à Montréal, comme à l'échelle de la province, les anglophones étaient surreprésentés dans les classes possédantes, dans les classes instruites et parmi les ouvriers qualifiés. Certains groupes, parmi eux, étaient plus pauvres que les Canadiens français mais, dans l'ensemble, ils étaient, par une marge considérable à Montréal et ailleurs, les plus riches. Ils étaient donc moins prolifiques et moins sujets à la maladie et à une mort précoce qu'eux. Leur croissance naturelle étant beaucoup moins vigoureuse que celle des francophones, ils dépendaient pour l'expansion de leur population d'une façon essentielle de l'apport migratoire.

Il va de soi que c'est à Montréal, centre même de la diversité ethnique, religieuse et sociale, où tous ces facteurs, en constante interaction, contribuaient à modifier les profils des uns et des autres. Ainsi, entre 1851 et 1896 , l'indice de mortalité générale fut de $100 \mathrm{chez}$ les Britanniques, de $133 \mathrm{chez}$ les Irlandais

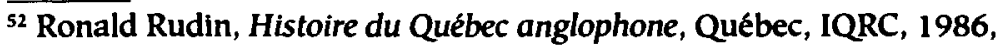
p. 219. 
TABLEAU 8

Natalité et mortalité chez les catholiques

et les protestants du Québec

(en pourcentage)

\begin{tabular}{ccccc}
\hline & \multicolumn{2}{c}{ natalité } & \multicolumn{2}{c}{ mortalité } \\
1891 & catholiques & protestants & catholiques & protestants \\
1901 & 3,42 & 2,36 & 1,95 & $?$ \\
1911 & 2,92 & 1,85 & 1,96 & $?$ \\
& 3,21 & 2,32 & 1,59 & $?$
\end{tabular}

Sources: données sur la natalité corrigées selon les indications de $\mathbf{R}$. Kuczynski, Op. cit., p. 58-61.

et de 196 chez les Canadiens français ${ }^{53}$. Le tableau 9 démontre cependant que cet écart, qui s'étendait à la mortalité infantile, diminua de 1880 à 1914 .

\section{TABLEAU 9}

Mortalité générale et infantile à Montréal de 1880 à 1914 (mortalité générale: pour 100 personnes; mortalité infantile: pour 100 naissances)

\begin{tabular}{cccccc}
\hline & \multicolumn{3}{c}{ mortalité générale } & \multicolumn{3}{c}{ mortalité infantile } \\
anglo. & franco. & franco. & cath. angl. & protestants \\
$1880-1896$ & 1,70 & 3,02 & 27,2 & 19,6 & 17,2 \\
$1897-1914$ & 1,54 & 2,33 & 23,4 & 20,3 & 13,1 \\
& & & & &
\end{tabular}

Sources: D'après les chiffres de Martin Tétrault, «Les Maladies de la misère. Aspects de la santé publique à Montréal, 1880-1914", RHAF, vol. 36, 1983, pp. 509s., 512.

\section{II - LA DEMOGRAPHIE ACADIENNE}

Même si l'Acadie du XIX ${ }^{\mathrm{e}}$ siècle n'avait pas eu son Cyprien Tanguay pour dépouiller ses registres des mariages, des naissances et des décès depuis les origines, elle eut néanmoins ses historiens qui, en s'appuyant sur les données des recensements et

${ }^{53}$ Noël Bélanger et al., Les Travailleurs québécois, 1851-1896, Montréal, PUQ 1975, p. 51. 
autres documents semblables, proclamèrent que, pour l'essentiel, la croissance démographique de la colonie témoignait de l'extraordinaire fécondité des couples et de l'exceptionnelle salubrité du pays. «L'Acadie, disait Rameau de Saint-Père en 1889, ne reçut même pas 400 colons immigrants, de 1630 à $1710^{54}$.» En 1924, Emile Lauvrière renchérit sur son prédécesseur en déclarant que le Sieur d'Aulnay, mort en 1650, avait:

définitivement enraciné la race française en cette région... C'est de cette quarantaine de femmes françaises qu'est, en fait, sortie à peu près toute la race acadienne... car il ne se fixa guère jusqu'en 1714 qu'une cinquantaine d'autres colons français, presque tous célibataires ${ }^{55}$.

Ce discours sur la médiocrité de l'apport migratoire et sur la haute fertilité des pionnières en dit plus long sur la faiblesse de la population en cause au $\mathrm{XVII}^{\mathrm{e}}$ siècle, environ 440 habitants en 1671,932 en 1686 et 2908 en 1714, que sur le peu d'effet du facteur immigration sur la croissance démographique. En effet, pendant ces années, le taux moyen de la croissance fut de $4,90 \%$ par an, soit un niveau de $80 \%$ supérieur à celui de la Nouvelle-France, lui-même déjà influencé par l'immigration. À n'en pas douter, comme Andrew Clark l'avait supposé en 1968, l'apport de l'immigration à la croissance des effectifs fut beaucoup plus considérable que ces historiens ne l'ont prétendu ${ }^{56}$.

Après 1713, avec l'intrusion de l'île-Royale dans les pêcheries et le commerce nord-atlantiques par le biais de Louisbourg, les mouvements migratoires s'accrurent en intensité. D'autant plus qu'après la

${ }^{54}$ Rameau de Saint-Père, op cit., vol. I, p. 280.

${ }^{55}$ Lauvrière, op. cit., vol. I, p. 78.

${ }^{56}$ Andrew Hill Clark, The Geography of Early Nova Scotia to 1760 , Madison, University of Wisconsin, 1968, p. 131. 
cession à l'Angleterre, même Port-Royal continua à recevoir des immigrants de France, quoiqu'en pourcentage toujours plus infime. Et cela, même si, depuis la fin du XVII ${ }^{e}$ siècle, Port-Royal était devenu un foyer de migrations vers l'intérieur et, plus tard, vers l'Acadie française. À ce sujet, Gisa Hynes raconte que $21 \%$ des mâles nés avant 1650 quittèrent la région pour aller coloniser l'intérieur et que ceux qui étaient nés entre 1660 et 1670 posèrent le même geste dans plus de la moitié des cas ${ }^{57}$. Ce tarissement de l'immigration aurait suscité un accroissement rapide des mariages consanguins et de l'analphabétisme. Ainsi, à Port-Royal, le taux moyen de croissance de la population ne fut finalement, de 1671 à 1748 , que de 1,7\% par an, alors qu'en des lieux qui recevaient des migrants, comme les Mines et Beaubassin, il se tint à 9,3\% et $11,7 \%$ respectivement de 1686 à 1748 . Si on scrute de près les chiffres de population mentionnés par les historiens, le taux moyen de croissance de la population de l'ensemble des deux Acadies fut nettement supérieur à celui de la Nouvelle-France $(3,7 \%$ par an contre $3 \%)$ où, contrairement aux Acadies, l'immigration fut modeste. En effet, en 1713, seulement quelques résidents sur l' ̂lle-Saint-Jean et 140 au Cap-Breton. Sur l'île-Saint-Jean, où le taux de masculinité était encore de 149 en 1728, la population s'accrut, grâce à des apports migratoires venus de France et, plus tard, en nombre croissant de l'Acadie anglaise. En 1735 , les migrants acadiens représentaient $35 \%$ d'une population se chiffrant à près de 600 personnes $^{58}$. Puis, cette proportion grimpa lorsque la population

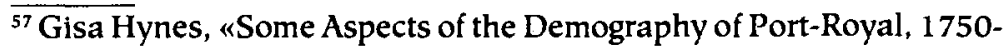
$1755 »$, Acadiensis, III, 1973, p. 5.

${ }_{58}$ Georges Arseneault, Les Acadiens de l'île, 1720-1980, Moncton, Éditions d'Acadie, 1987, p. 23. 
augmenta presque subitement à 1000 habitants en 1749 et à 2969 en 1752 .

Pendant ce temps, se produisit, principalement sous l'égide des colons de Louisbourg, l'insertion rapide de l'île-Royale dans les pêcheries et le commerce nord-atlantiques. Aussi la population du CapBreton augmenta-t-elle rapidement sous l'effet de l'immigration: de 140 habitants en 1713 à 2012 en 1719 , puis à 4618 en 1737 et à 5845 en 1752 . Ces migrants, des célibataires et des familles, venaient principalement de France, de Terre-Neuve et de l'Acadie anglaise. Il va de soi que les premiers contingents qui quittèrent Port-Royal en 1713 pour l'île-Royale étaient des administrateurs et des militaires ${ }^{59}$. Ceux qui les suivirent se recrutèrent plutôt parmi les fils de paysans, d'artisans et de pêcheurs. Sur l'île, en dehors de Louisbourg, la population, formée d'agriculteurs, de pêcheurs, de navigateurs et de salariés, s'éleva à 2655 en 1737, pour ensuite retomber à 1671 en 1752. À cette date, selon Pouyez, seulement $19 \%$ des habitants étaient nés dans l'île, $30 \%$ en Acadie anglaise et $46 \%$ en France et autres pays ${ }^{60}$. Il n'est donc pas surprenant, étant donné la forte proportion de célibataires parmi ces immigrants, que le taux de masculinité ait encore été de $146 \%$ à cette date.

Il l'était plus encore à Louisbourg, où résidait une population flottante, surtout constituée d'une garnison militaire et de soldats aux effectifs variables et mal consignés. Par contre, la croissance de la population

\footnotetext{
${ }^{59}$ Bernard Pothier, «Acadian Emigration to Île Royale after the Conquest of Acadia», Histoire sociale/Social History, III, 1970, pp. 120s.; B.A. Balcom, The Cod Fisheries of Isle Royale, 1713-1758, Ottawa, Pares Canada, 1984.

${ }^{60}$ Christian Pouyez, «La Population de l'île-Royale en $1752 »$, Histoire sociale/Social History, VI, 1973, p. 147-180.
} 
civile ${ }^{61}$ y fut soutenue: $7,7 \%$ en moyenne par an de 1715 à 1752 . Au total, entre 1714 et 1758,200 marchands œuvrèrent à Louisbourg et seulement une douzaine dans le reste de l'île ${ }^{62}$. Les artisans, les manœuvres et les pêcheurs y furent en plus grand nombre encore.

Ainsi, à la veille de la déportation, les deux Acadies avaient des sociétés et des économies encore peu développées, mais relativement diversifiées et prospères. L'Acadie sous domination anglaise connaissait en plus la diversité ethnique et religieuse, situation propice à une différenciation accrue des profils démographiques. À Port-Royal, selon Gisa Hynes, la famille acadienne moyenne, la seule étudiée jusqu'à maintenant, ressemblait assez à celle de la Nouvelle-France. Dans les familles complètes, dont l'intégrité n'avait pas été affectée par la mort de l'un des conjoints, le nombre d'enfants était de 10,5 lorsque la femme s'était mariée avant l'âge de vingt ans. Si elle s'était mariée entre 20 et 24 ans, le nombre de ses enfants se chiffrait à 9 et, si le mariage avait eu lieu entre 25 et 29 ans, à 7,5. L'âge moyen au mariage était de 21 pour les femmes et de 26 pour les hommes. Comme le niveau de la mortalité ne semble pas avoir été différent de ce qu'il était en Nouvelle-France, la croissance naturelle y eut à peu près la même vigueur dans une colonie que dans l'autre ${ }^{63}$. Notons que ce profil était substantiellement différent de celui des habitants de la Connecticut River Valley, Massachusetts, à la même époque: un âge au mariage à peu près semblable, mais 2,3 enfants de moins

${ }^{61}$ A.H. Clark, The Geography of..., p. 276.

${ }^{62}$ Christopher Moore, «Merchant Trade in Louisbourg, Île Royale", M.A. Thesis, Un. of Ottawa, 1977, 144 p.

${ }^{63}$ Hynes, "Some Aspects...», p. 9-17. 
DÉMOGRAPHIE DES COMMUNAUTÉS FRANCOPHONES

ici que là et des intervalles entre les naissances plus longs en moyenne de plus de 6 mois dans la colonie américaine ${ }^{64}$.

Entre 1755 et 1763 , cette société fut bouleversée par l'énorme événement de la déportation et de l'errance. Lauvrière estime le nombre des déportés à 10500 et des errants à 3500 , chiffres qui ne sont pas tellement différents de ceux de Rameau de Saint-Père. Des 12660 survivants dénombrés en Europe et dans les Amériques en 1763, environ 2900 habitaient dans les Maritimes, plus de la moitié d'entre eux étant rassemblés dans la Nouvelle-Écosse actuelle, un tiers au Nouveau-Brunswick et le reste dans l'île-SaintJean $^{65}$. En 1803 , ces pourcentages seront, dans l'ordre, de $47 \%, 44 \%$ et $9 \%$.

La reconstruction de la société acadienne débuta donc autour d'un petit noyau de survivants moins concentrés en Nouvelle-Écosse qu'autrefois, auxquels viendront s'ajouter, au fil des ans, des rapatriés. Ainsi, Rameau de Saint-Père mentionne le retour, en 1766, de 1500 exilés venus des États-Unis. Vu sous cet angle, le rétablissement de la société acadienne se déroula dans le cadre d'un mouvement plus large de peuplement réalisé, à l'échelle des Maritimes, par des immigrants d'origine ethnique, religieuse et géographique diverse parmi lesquels les Acadiens n'étaient qu'un groupe parmi d'autres. Cela est si vrai que leur taux de croissance, au moins le double

${ }^{64} \mathrm{H}$. Temkin-Greener and A.C. Swedlund, «Fertility and Transition in the Connecticut Valley, 1740-1850", Population Studies, vol. 32, 1978, p. 27-41.

${ }^{65}$ Ouellet, «Démographie, développement économique, fréquentation scolaire et alphabétisation dans les populations des Maritimes avant 1911: une perspective régionale et comparative", Acadiensis, XXVI, 1996, p. 3-31. 
de celui du Québec d'origine française, ne fut pas différent de celui de la population de la région, également alimentée par une immigration substantielle: des taux de 6,8\% par an pour les Acadiens et de 7,1\% pour les Maritimes de 1763 à 1860 .

Donc, ces Acadiens pauvres, illettrés et sans force politique, constituant maintenant une minorité à la fois semblable et différente des autres, tentèrent de se tailler un espace où ils pourraient se regrouper, remettre sur pied leur économie et réaménager leurs institutions. Sur ce territoire, bientôt divisé en plusieurs colonies, ils se déplacèrent en des lieux où ils eurent, à peu près partout, accès aux trois grandes ressources de la région: la mer, la terre et la forêt. Un siècle plus tard, cet effort soutenu de rassemblement et de reconstruction les avait acheminés vers l'est et le nord du Nouveau-Brunswick. Ainsi, depuis 1763, leur proportion en Nouvelle-Écosse et sur l'Île-duPrince-Édouard avait chuté à $39 \%$ et $13 \%$ respectivement, mais s'était, par contre, accrue à $48 \%$ au Nouveau-Brunswick. Au contraire, plus de la moitié des non-francophones restaient solidement enracinés en Nouvelle-Écosse, ce qui les laissait au Nouveau-Brunswick et à l'Île-du-Prince-Édouard dans des proportions de $37 \%$ et $12 \%$ respectivement.

Au Québec, en Ontario et dans les Maritimes, les années 1850-1911 marquèrent un ralentissement considérable de la croissance de la population (tableau 10). Comme la population anglophone n'augmenta que de $\mathbf{3 0} \%$ à l'est du Québec en $\mathbf{5 0}$ ans, le pourcentage de $41 \%$ d'accroissement des effectifs des Maritimes eut été impossible sans un apport des Acadiens dont le nombre s'accrut de $137 \%$ de 1861 à 1911 . Ce dynamisme des Acadiens était tout relatif et inégal 
puisqu'il leur fallut 40 ans avant qu'ils puissent euxmêmes doubler leur population. D'autant plus qu'en Nouvelle-Écosse et à l'île-du-Prince-Édouard, là où étaient concentrés $33 \%$ et $10 \%$ des Acadiens en 1911 , ils ne purent même pas absorber tous leurs surplus des naissances sur les décès. Pas étonnant que, dans ces deux provinces, ils aient pris 60 et 100 ans respectivement, après 1860 , avant de se multiplier par deux. Pendant ce temps, le Nouveau-Brunswick, principal bénéficiaire de ces migrations, rassemblait en ses frontières $60 \%$ des Acadiens de la région. Ainsi, vers 1893, il y avait deux fois plus d'Acadiens dans cette province qu'en 1860 .

TABLEAU 10

Taux de croissance de la population des Maritimes (1860-1911) (en pourcentage annuel)

\begin{tabular}{lcccc}
\hline & Nouveau- & Nouvelle- & Île-du- & Maritimes \\
& Brunswick & Ecosse & Pr.-Edouard & \\
Acadiens & 2,32 & 1,21 & 0,77 & 1,75 \\
anglophones & 0,26 & 0,68 & 0,17 & 0,47 \\
ensemble & 0,62 & 0,73 & 0,24 & 0,63 \\
& & & &
\end{tabular}

Sources: Recensements du Canada.

Si la croissance de la population anglophone des Maritimes fut tellement médiocre, c'est qu'elle reposa entièrement sur la modeste performance $(45 \%$ d'augmentation en un demi-siècle) des Néo-Écossais. Car, comme cela arriva alors parmi les anglophones de l'est de l'Ontario, il y eut même, au NouveauBrunswick et dans l'île, après 1881 , un déclin absolu (29 040 individus) des effectifs anglophones et, forcément, émigration vers l'extérieur de la région.

À l'intérieur de chaque province, les Acadiens s'étaient aussi, avec le temps, déplacés vers certains 
endroits bien précis. Ainsi, en 1901, 91\% des Acadiens du Nouveau-Brunswick, $76 \%$ de ceux de la Nouvelle-Écosse et $69 \%$ de ceux de l'île s'étaient regroupés dans les comtés dits acadiens. Dans ces comtés, où l'intensité de leur présence variait d'une localité à l'autre, leur proportion dans la population locale s'établissait à $47 \%, 18 \%$ et $24 \%$ respectivement. Leurs affinités avec les lieux étaient, à bien des égards, d'autant plus renforcées que d'autres minorités catholiques y résidaient. Les effectifs de ces éléments catholiques anglophones vivant dans les concentrations acadiennes s'établissaient à $16 \%$ au NouveauBrunswick, à $8 \%$ en Nouvelle-Écosse et à $18 \%$ sur l'Île-du-Prince-Édouard.

Plus récemment encore, à la suite des Québécois, des Ontariens et des habitants de leur région, ils s'étaient en plus engagés dans le mouvement vers les villes et les emplois manufacturiers. Comme ils étaient surtout localisés dans les régions les plus rurales et plus concentrés que les autres dans les industries primaires et les emplois saisonniers, ils s'urbanisèrent plus lentement et moins intensément que leurs compatriotes, même que leurs voisins anglophones immédiats (tableau 11). Étant sous-représentés dans l'univers politique, les professions les plus prestigieuses et les occupations les plus lucratives, ils furent à peu près partout sous-représentés en milieu urbain, mais, particulièrement, à Halifax, Charlottetown, SaintJean et Fredericton. Notons toutefois qu'en dehors de leurs propres territoires, ils furent partout plus urbains qu'ils ne l'étaient chez eux.

Il va de soi que tous ces changements arrivés depuis 1763 se répercutèrent sur le comportement démographique des Acadiens, aussi bien que sur celui 
TABLEAU 11

Urbanisation des provinces maritimes en 1901

(taux en pourcentage)

\begin{tabular}{|c|c|c|c|c|}
\hline & $\begin{array}{l}\text { Nouveau- } \\
\text { Brunswick }\end{array}$ & $\begin{array}{c}\text { Nouvelle- } \\
\text { Ecosse }\end{array}$ & $\begin{array}{l}\text { île-du- } \\
\text { Pr.-Ed. }\end{array}$ & Maritimes \\
\hline \multicolumn{5}{|l|}{ Province } \\
\hline Acadiens & 5,1 & 10,9 & 8,9 & 7,4 \\
\hline non-Acadiens & 29,6 & 26,3 & 16,6 & 26,2 \\
\hline ensemble & 23,7 & 24,8 & 15,5 & 23,3 \\
\hline \multicolumn{5}{|l|}{ Comtés acadiens } \\
\hline Acadiens & 4,1 & 9,7 & 5,4 & 5,7 \\
\hline non-Acadiens & 19,7 & 48,9 & 7,7 & 32,0 \\
\hline ensemble & 12,3 & 34,2 & 7,2 & 30,0 \\
\hline \multicolumn{5}{|c|}{ Comtés non acadiens } \\
\hline Acadiens & 15,4 & 13,9 & 16,6 & 14,8 \\
\hline non-Acadiens & 34,3 & 20,2 & 21,2 & 35,4 \\
\hline ensemble & 33,5 & 19,9 & 20,9 & 24,5 \\
\hline
\end{tabular}

Sources: Recensements du Canada.

de la population environnante. Il est cependant difficile de mesurer l'ampleur de ces changements, puisque personne n'a tenté jusqu'à ce jour de dépouiller les registres des mariages, des baptêmes et des sépultures catholiques de la région, en vue d'accumuler, pour les Maritimes, un ensemble de données continues comparable à celles que Mgr Tanguay avait produites pour le Québec. Le même problème se pose aussi pour les protestants, groupe encore plus divers sur le plan ethnique que les catholiques. Ainsi, dans l'état actuel de la recherche, il est impossible de proposer des séries continues de taux de nuptialité, de natalité et de mortalité diversifiées selon l'appartenance religieuse avant le $\mathrm{XX}^{\mathrm{e}}$ siècle.

En l'absence de ce corpus chiffré qui aurait permis de mieux mettre en rapport l'évolution démographique avec, si possible, celle de la diversité religieuse, ethnique et socioéconomique des lieux, il faut donc s'en remettre aux recensements décennaux. Et cela, 
en assumant qu'ils ne sont pas plus imparfaits pour les Maritimes et l'Ontario que pour le Québec. Mais que faire pour les années 1763-1850, époque où, à peu près partout, les recensements, quand ils existaient, étaient presque toujours silencieux sur les trois variables de la croissance naturelle? Sinon, de nous en tenir à des approximations faites à partir de quelques indicateurs structuraux.

Le plus nombreux de ces groupes, celui des nonfrancophones, eut, à notre avis, un comportement qui se situait entre celui des habitants de la Nouvelle-Angleterre et celui des Acadiens. Même si, à l'origine, ces Maritimiens ont pu reproduire leurs antécédents américains, ils n'avancèrent pas au même rythme que leurs voisins dès le moment où ces derniers s'engagèrent, plus vite qu'on l'aurait cru, dans le processus de la transition démographique. En effet, selon Nancy Osterud et John Fulton, les habitants de Sturbridge, au Massachusetts, attirés dans cette direction par le développement de l'économie de marché et, ensuite, par l'avènement industriel, entreprirent de limiter la dimension de leur descendance entre 1730 et 1839 . Au cours de ce siècle, le nombre moyen d'enfants dans les familles complètes $y$ descendit de 8,83 à 5,30 , pendant que l'âge moyen des femmes au mariage s'éleva de 20,6 ans à $24,4^{66}$. La même évolution vers le contrôle volontaire des naissances, pratiqué de plusieurs façons décrites par un contemporain, le Dr Knowlton, a été identifiée par H. Temkin-Greener et A.C. Swedlung dans leur étude sur trois communautés de la Connecticut River Valley, où le taux de la natalité déclina, entre 1740 et

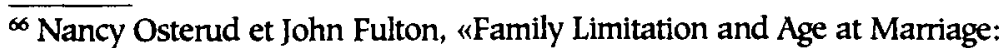
Fertility Decline in Sturbridge, Massachusetts, 1730-1850», Population Studies, vol. 30, 1976, p. 481-494. 
1850 , de $4,98 \%$ à $1,75 \%$ et où le nombre moyen d'enfants par famille complète s'abaissa, entre 1721 et 1800 , de 7,2 à $5^{67}$. Notons ici, pour illustrer notre point sur la lenteur relative du déclin à long terme de la natalité parmi les anglophones des Maritimes par rapport aux Américains, que, durant la décennie 1921-1931, la natalité moyenne, au NouveauBrunswick, se situait encore, selon Muriel Roy, à $2,20 \% \mathrm{chez}$ les non-francophones et à $3,70 \% \mathrm{chez}$ les Acadiens ${ }^{68}$.

De leur côté, les Acadiens semblent avoir maintenu après 1763 leur comportement traditionnel, tel que décrit par Gysa Hines à propos de Port-Royal, et, dès lors, avoir suivi un itinéraire proche de celui des Canadiens français de la vallée du Saint-Laurent, à savoir une natalité et une mortalité plus fortes que celle de la population protestante. Ils eurent d'ailleurs, selon leur province de résidence et leur lieu d'habitation à l'intérieur de chacune d'elles, dans et hors des concentrations, des taux sensiblement différents les uns des autres, différents aussi de ceux des populations environnantes. En général, leurs taux de natalité et de mortalité générale et infantile furent toujours plus hauts, là où ils étaient les plus nombreux et regroupés, c'est-à-dire dans le nord et l'est du Nouveau-Brunswick, que partout ailleurs dans la région. Ces distinctions régionales, déjà observées au Québec, traversent l'histoire des Maritimes. Enracinées avec le temps, elles se perpétuèrent jusqu'au milieu du $\mathrm{XX}^{\mathrm{e}}$ siècle (tableau 12).

${ }_{67}$ Temkin-Greener and Swedlund, «Fertility Transition in the Connecticut Valley, 1740-1850», Population Studies, vol. 32, 1978, p. 27-41. ${ }^{68}$ Muriel Roy, "Peuplement et croissance démographique en Acadie", Jean Daigle (dir.), Les Acadiens des Maritimes, Moncton, Chaire d'études acadiennes, 1980 , p. 182. 
TABLEAU 12

Taux de natalité et de mortalité chez les Acadiens et les habitants d'origine britannique en 1921

(en pourcentage)

\begin{tabular}{lcccc}
\hline & \multicolumn{2}{c}{ natalité } & \multicolumn{2}{c}{ mortalité } \\
& Acadiens & $\begin{array}{c}\text { Britan- } \\
\text { niques }\end{array}$ & Acadiens & $\begin{array}{c}\text { Britan- } \\
\text { niques }\end{array}$ \\
N.-Brunswick & $\mathbf{4 , 0 0}$ & $\mathbf{2 , 4 3}$ & 1,50 & 1,35 \\
N.-Ecosse & 2,74 & 2,52 & 1,15 & 1,28 \\
Île-du-Pr.-Ed. & 2,80 & 2,30 & 1,41 & 1,30 \\
Maritimes & 3,55 & 2,46 & 1,39 & 1,31 \\
\hline
\end{tabular}

Sources: Statistiques vitales canadiennes, 1921 .

En s'en reportant aux recensements décennaux d'avant 1915 pour éclairer cette évolution et ces inégalités depuis 1850, il faut se rappeler que les informations communiquées aux recenseurs à ce sujet le furent partout, soit directement par les curés, les ministres protestants ou les rabbins, soit par l'entremise des employés municipaux, des responsables de la santé publique et des fonctionnaires affectés à l'enregistrement des données. Il est certain qu'avant la mise en place par l'État fédéral d'un système fiable pour l'enregistrement et la collecte des informations vitales, la précision des renseignements fournis variait davantage selon le zèle de ces intermédiaires. Il faut aussi se rappeler que le Québec est le seul endroit où on peut assez facilement tester la valeur des chiffres inscrits à cette fin dans les recensements, puisqu'il s'agit alors de les comparer avec ceux tirés plus directement des registres paroissiaux catholiques. Ce qui ne veut pas dire que, malgré leur caractère massif et continu, les données extraites de ces registres étaient tout à fait irréprochables. En effet, des événements de toutes sortes avaient, depuis le XVII ${ }^{e}$ siècle, affecté l'enregistrement des actes, leur préservation 
et le processus de la transmission des informations. Ces incidences avaient donné lieu à une certaine sous-estimation, variable d'une période à l'autre, non seulement du nombre des naissances, mais, surtout, du nombre des décès. Ces lacunes, notées et corrigées jusqu'à un certain point par les démographes dans leurs études, ont été quantifiées par Robert Kuczynski en ce qui concerne les rapports du Conseil d'hygiène du Québec sur les naissances catholiques et protestantes enregistrées au cours des années 1884$1911^{69}$.

Cette analyse de Kuszynski portait sur les événements qui avaient amené le gouvernement des Canadas à vouloir créer, en 1865, un organisme affecté à l'enregistrement des actes et à la production des statistiques vitales pour tout le pays. Après la Confédération, tout en reconnaissant que l'enregistrement des actes était une affaire provinciale, le gouvernement fédéral maintint néanmoins son droit de produire ces statistiques vitales nationales. Mais il se heurta au clergé catholique québécois et aux provinces qui, tour à tour, passèrent leurs propres législations, dont l'efficacité resta douteuse jusqu'au début du siècle. Aussi le projet fédéral demeura-t-il lettre morte jusqu'à la création en 1915 du bureau fédéral de la statistique qui, parmi ses attributions, eut celle de recueillir les statistiques vitales. En 1921, le Québec rejeta le plan fédéral à cet égard, mais, trois ans plus tard, il se plia volontiers aux exigences de la loi fédérale passée la même année ${ }^{70}$.

La décision du gouvernement québécois d'intervenir parallèlement dans la compilation systématique

${ }^{69}$ Kuczynski, Birth Registration, p. 53-61.

${ }^{70}$ Ibid., p. 4-14, 50, 53, 61, 62. 
des statistiques vitales avait été précipitée par l'épidémie de picote de 1885. Car le Conseil d'hygiène, créé en 1887 à la demande du corps médical, avait décidé d'accumuler, à partir des registres tenus par les ministres du culte, les informations relatives aux causes de la mortalité locale. Comme le clergé catholique voyait dans cette initiative un danger pour son monopole sur la tenue des actes de l'état civil et pour son contrôle sur la moralité des actes médicaux, il fallut, comme le disent Pouyez et Lavoie, quatre projets de loi avant qu'une législation appropriée ne fut adoptée en 1893. Même là, quand la loi fut passée, il fallut une vingtaine d'années avant que le clergé n'acceptât de vraiment collaborer ${ }^{71}$.

Quoi qu'il en soit, dans chacune des provinces maritimes, entre 1864 et 1918 , il y eut bien des législations, remodelées au cours des ans, visant à l'enregistrement et à la compilation des données vitales. Mais il ne semble pas, d'après ce qu'en dit Kuczynski, que cet effort ait eu tous les résultats attendus. Ainsi, dans les provinces anglophones, les recensements, que Pouyez et Lavoie décrivent finalement comme "une honnête source de données socioéconomiques ${ }^{72} »$, constituent, dans l'état actuel de la recherche, la source publiée la plus aisément accessible d'informations sur la croissance naturelle de la population entre 1850 et 1915 .

Mais toutes imparfaites qu'elles soient, les données incluses dans les compilations de Tanguay et du Conseil d'hygiène sur les catholiques québécois sont suffisamment solides, une fois confrontées avec celles des recensements qui portent sur l'ensemble de la popu-

${ }^{11}$ Pouyez et Lavoie, Les Saguenayens, p. 3, 60-65.

${ }^{72}$ Ibid., p. 34. 
lation, pour mettre en évidence les carences et les avenues d'utilisation des recensements non seulement pour le Québec (tableau 13) mais pour les autres provinces (voir tableaux 18 et 19 ).

\section{TABLEAU 13}

Comparaison entre (1) les naissances et les décès catholiques et (2) les chiffres des recensements sur les naissances et les décès dans l'ensemble de la population du Québec (1851-1901)

\begin{tabular}{rccrccr}
\hline & \multicolumn{3}{c}{ naissances } & \multicolumn{3}{c}{ décès } \\
1851 & 34066 & 36719 & +2653 & 14165 & 10769 & -3396 \\
1861 & 42856 & 40767 & -2089 & 17366 & 12839 & -4527 \\
1871 & 44730 & 45813 & +1083 & 20934 & 20813 & -21 \\
1881 & 50484 & 53018 & +2534 & 27465 & 26074 & -1391 \\
1891 & 57938 & & & 33007 & 28480 & -4528 \\
1901 & 55398 & 58651 & +3253 & 32219 & 30410 & -1809
\end{tabular}

Sources: Recensement du Canada, 1871, vol. 5; Recensements du Canada 1851-1901.

On aura noté qu'en 1871 et 1881 le nombre des baptêmes catholiques est seulement légèrement inférieur au nombre des naissances inscrites au recensement qui inclut à la fois les catholiques et les non-catholiques. À une occasion même, soit en 1861, les naissances catholiques surpassent substantiellement le nombre total des naissances, ce qui tend à réduire les taux. Il est encore plus remarquable que le nombre des décès catholiques soit toujours supérieur au nombre total des décès. Il est évident, d'après ces chiffres et d'après ce que Kuczynski en dit, que ce sous-dénombrement des naissances et, plus encore, des décès s'applique aussi bien aux non-catholiques qu'aux catholiques.

Étant donné ces problèmes qui affectent inégalement chacun des recensements, on ne saurait les 
utiliser pour y lire une évolution précise des taux, surtout de ceux de mortalité, entre 1871 et 1911 . Comme il n'y a pas lieu de supposer que les recenseurs de certaines provinces auraient pu être sousinformés et les autres pas, on peut assumer, ainsi que nous l'avons fait remarquer dans un texte précédent à propos des données sur la fréquentation scolaire et l'alphabétisation ${ }^{73}$, que les indications structurelles tirées de cette source, de même que les comparaisons interrégionales dans chaque province et interprovinciales dans l'ensemble du pays, sont instructives. Ce point de vue est confirmé par Pouyez et Lavoie qui concluent leur examen en disant que les recensements «sont susceptibles de traduire plus correctement les aspects structurels de la population que son mouvement ${ }^{74} »$. D'ailleurs, ce sont des aspects qui émergent aussi bien des statistiques vitales de 1931 que de celles des dénombrements antérieurs. Comme le démontre le tableau 14, il n'y pas contradiction entre les deux ensembles chiffrés.

Disons d'abord qu'au Québec où la densité francophone et catholique, ainsi que la concentration urbaine, étaient plus considérables que dans les comtés dits acadiens, les taux de natalité et de mortalité générale et infantile étaient supérieurs à ce qu'ils étaient dans ces comtés et dans l'ensemble des Maritimes. Ajoutons que ces taux, excepté celui de la mortalité générale en 1931, étaient dans les comtés dits acadiens plus élevés que ceux qui prévalaient dans les comtés dits anglophones toujours plus urbanisés qu'eux. Notons toutefois que les Acadiens

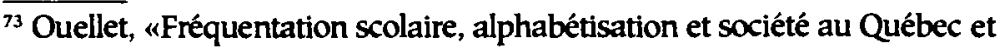
en Ontario jusqu'en 1911: les francophones et les autres", Cahiers Charlevoix 2, p. 312-314.

${ }^{74}$ Pouyez et Lavoie, op. cit., p. 34. 
TABLEAU 14

Natalité, mortalité générale et infantile dans les Maritimes de 1871 à 1931 (en pourcentage)

\begin{tabular}{|c|c|c|c|c|}
\hline & 1871 & 1881 & 1901 & 1931 \\
\hline $\begin{array}{l}\text { comtés acadiens } \\
\text { Nouveau-Brunswick }\end{array}$ & & & & \\
\hline natalité & 3,65 & 3,54 & 3,03 & 3,08 \\
\hline mortalité & 1,25 & 1,67 & 1,28 & 1,08 \\
\hline croissance & 2,40 & 1,87 & 1,75 & 2,00 \\
\hline $\begin{array}{l}\text { mortalité infantile } \\
\text { Nouvelle-Écosse }\end{array}$ & 10,30 & 10,90 & 12,60 & 9,60 \\
\hline natalité & 3,29 & 3,04 & 2,39 & 2,11 \\
\hline mortalité & 1,37 & 1,72 & 1,32 & 1,24 \\
\hline croissance & 1,92 & 1,32 & 1,07 & 0,87 \\
\hline $\begin{array}{l}\text { mortalité infantile } \\
\text { Île-du-Prince-Édouard }\end{array}$ & 9,20 & 9,40 & 9,60 & $\mathbf{8 , 5 0}$ \\
\hline natalité & 2,88 & 3,48 & 2,44 & 2,47 \\
\hline mortalité & 0,94 & 1,86 & 1,12 & 1,04 \\
\hline croissance & 1,94 & 1,62 & 1,32 & 1,43 \\
\hline $\begin{array}{l}\text { mortalité infantile } \\
\text { Maritimes }\end{array}$ & 8,10 & 6,20 & 8,10 & \\
\hline natalité & 3,40 & 3,40 & 2,75 & 2,81 \\
\hline mortalité & 1,24 & 1,71 & 1,27 & 1,11 \\
\hline croissance & 2,16 & 1,69 & 1,48 & 1,70 \\
\hline $\begin{array}{l}\text { mortalité infantile } \\
\text { comtés anglophones } \\
\text { Nouveau-Brunswick }\end{array}$ & 9,90 & 10,10 & 11,00 & 9,30 \\
\hline natalité & 3,03 & 2,71 & 2,22 & 2,10 \\
\hline mortalité & 1,24 & 1,39 & 1,05 & 1,21 \\
\hline croissance & 1,79 & 1,32 & 1,17 & 0,89 \\
\hline $\begin{array}{l}\text { mortalité infantile } \\
\text { Nouvelle-Écosse }\end{array}$ & 8,50 & 8,40 & 7,90 & 7,20 \\
\hline natalité & 2,96 & 2,78 & 2,31 & 2,29 \\
\hline mortalité & 1,22 & 1,42 & 1,13 & 1,15 \\
\hline croissance & 1,74 & 1,36 & 1,18 & 1,14 \\
\hline $\begin{array}{l}\text { mortalité infantile } \\
\text { Île-du-Prince-Édouard }\end{array}$ & 9,00 & 8,60 & 7,60 & 7,80 \\
\hline natalité & 2,17 & 2,77 & 1,89 & 1,95 \\
\hline mortalité & 1,02 & 1,24 & 1,16 & 1,03 \\
\hline croissance & 1,15 & 1,53 & 1,73 & 1,92 \\
\hline $\begin{array}{l}\text { mortalité infantile } \\
\text { Maritimes }\end{array}$ & 7,90 & 7,60 & 5,90 & \\
\hline natalité & 2,90 & 2,76 & 2,25 & 2,06 \\
\hline mortalité & 1,21 & 1,39 & 1,11 & 1,16 \\
\hline croissance & 1,69 & 1,37 & 1,14 & 0.90 \\
\hline mortalité infantile & 8,80 & 7,60 & 7,70 & 8,00 \\
\hline
\end{tabular}

Sources: Recensements du Canada, 1871-1901, et Statistiques vitales, 1931. 


\section{FERnAND Ouellet}

vivant en concentration anglophone et habitant plus souvent en ville que les Acadiens des aires francophones avaient une mortalité générale qui, selon le recensement de 1901, aurait été plus faible que celle des catholiques et des protestants.

Comme la majorité des Acadiens était rassemblée sur une portion du Nouveau-Brunswick moins urbanisée que son équivalent en Nouvelle-Écosse, la natalité et la mortalité infantile étaient plus hautes là qu'ici, mais la mortalité générale y était plus basse. Dans l'île-du-Prince-Édouard, province plus rurale, les Acadiens avaient une natalité et des mortalités générale et infantile plus faibles qu'au NouveauBrunswick.

Même si on peut déceler à travers ces chiffres une modeste baisse de la natalité parmi les Acadiens au tournant du siècle, on ne saurait en conclure que, excepté parmi certains éléments urbains, ils auraient pratiqué le contrôle volontaire des naissances à cette époque. Un déclin aussi minime pourrait fort bien s'expliquer par une émigration, même modeste.

\section{III - Ontariens et Ontariens d'origine française}

À la fin de la Révolution américaine, environ 6000 Loyalistes vinrent s'établir en Ontario, territoire qui, depuis toujours, faisait partie d'un espace économique rattaché à Montréal, parsemé de postes de traite jusqu'aux Rocheuses et disputé de plus en plus victorieusement, au tournant du siècle, par les Américains et la Compagnie de la Baie d'Hudson. En tant que terre maintenant ouverte à une immigration nombreuse et socialement diversifiée, le développement du territoire situé en dehors du domaine de la 
Compagnie de la Baie d'Hudson fut dès lors de plus en plus articulé sur l'agriculture, sur le commerce et, éventuellement, sur l'industrie. Ainsi, en 1791, lorsque le gouvernement britannique fit du Haut-Canada une colonie séparée, quoique dépendante à nombre d'égards de la colonie voisine, la population avait déjà doublé.

Ce mouvement de peuplement s'accéléra considérablement par la suite, grâce à une immigration venue, dans un premier temps, des États-Unis, puis de plus en plus, après 1815 , des Îles Britanniques et, plus tard, des Canadiens français du Canada-Est. Entre 1805 et 1850 , le taux moyen annuel de croissance de la population s'éleva à $11,6 \%$. Le million d'immigrants, pour la plupart en quête de terres, ou autrement, d'un emploi et d'une clientèle, qui arriva dans les colonies anglaises entre 1815 et 1850 , se reclassa beaucoup moins souvent dans les colonies atlantiques et le Bas-Canada que dans le Haut-Canada et les États-Unis. Peuplé à ce rythme, le Canada-Ouest en arriva même à surpasser le Canada-Est avant le milieu du siècle.

Il va de soi qu'à cette époque, l'immigration fut le principal stimulant de la croissance démographique ontarienne. En effet, encore en 1851 , seulement $54 \%$ de la population était née dans la province, alors que le tiers des habitants nés à l'extérieur provenait d'Irlande, d'Écosse et d'Angleterre. Très divers par l'origine ethnique et géographique, les migrants anglophones l'étaient aussi par la religion. Parmi eux, les anglicans, les presbytériens et les méthodistes dominaient largement, alors que les catholiques formaient une modeste minorité gagnant sans cesse du terrain sur les autres. En somme, une colonie aux 
traditions culturelles variées qui contrastaient avec celles de la société beaucoup plus homogène et mature du Bas-Canada, où près de neuf habitants sur dix étaient nés dans la province. Où, aussi, les Canadiens français y prévalaient dans une proportion de $75 \%$ et les catholiques par une marge dépassant les $80 \%$.

Les immigrants venus en grand nombre de la Nouvelle-Angleterre eurent donc, au départ, une démographie qui ressemblait davantage à celle de leurs lieux d'origine plutôt qu'à celle de la population d'origine française. Ces distinctions entre la vallée du Saint-Laurent et la côte atlantique dataient de loin puisque, à Dedham, une localité puritaine de la Nouvelle-Angleterre, dont la population s'était accrue sans apport migratoire après 1648 , il avait fallu, selon Ken Lockridge, un demi-siècle pour que les effectifs ne doublent, alors que dans la vallée du Saint-Laurent, de 1681 à 1850 , ce résultat avait été obtenu tous les 27 ans $^{75}$.

L'immigration loyaliste, autant que celle originaire des Îles Britanniques, tranchait, non seulement en ce qui regarde la croissance naturelle, mais aussi, quant à sa composition, sur celle qui avait mis en marche le peuplement de la Nouvelle-France. Alors qu'à son arrivée au pays, l'immigration pionnière du XVII ${ }^{e}$ siècle était composée de célibataires dans une proportion de $84 \%$, celle du XIX ${ }^{e}$ siècle, tirée de l'intérieur ou de l'extérieur de la colonie, était, au contraire, formée de couples avec ou sans enfants. Ainsi, $94 \%$ des migrants partis de Charlevoix vers le

${ }^{75}$ Kenneth Lockridge, A New England Town. The First Hundred Years, New York, Norton Co, 1985, p. 65, 94. De 1648 à 1700, une croissance de 400 à 750; de 1686 à 1736, une augmentation de 600 à 1200 . 
Saguenay entre 1838 et 1911 étaient des personnes mariées, apparentées les unes aux autres et cultivateurs à $80 \%$. Une structure assez semblable se dégage des listes d'immigrants catholiques et protestants qui apparaissent à la fin de l'étude de Bruce Elliott sur les Irlandais venus de Tipperary Nord après 1819 vers les Canadas. Même si le taux de masculinité de ces 470 individus était, par une marge considérable, plus élevé qu'au Saguenay, $80 \%$ d'entre eux étaient des adultes mâles, mariés ou veufs. Dans la plupart des cas, il s'agissait de familles en formation, rythme de formation beaucoup plus lent qu'au Saguenay, puisque les 15 épouses dont l'âge est mentionné avaient 28,3 ans en moyenne et seulement 2,5 enfants $^{76}$. Ce qui laisse supposer des taux de fertilité inférieurs à ceux du Saguenay à la même époque. En effet, Elliott a pu identifier, sur le côté ontarien de la rivière des Outaouais, 141 familles constituées avant 1855 , dont les 451 fils, soit 3,2 par famille, avaient complété leur établissement en 1881. Ce qui, étant donné la longue durée de l'observation et leur taux de masculinité plutôt élevé au départ, ne permet pas de supposer une descendance moyenne supérieure à 7 enfants ${ }^{77}$.

Cette interprétation est confirmée de plusieurs façons par David Gagan qui, à propos des femmes du comté de Peel où les Irlandais étaient sans doute le groupe le plus nombreux en 1850, affirme:

Among the cohort of women, from persistent families, aged 20-4 in 1850 who began bearing children in the late 1840 s and who had completed their families by 1871 , the

${ }^{76}$ Bruce S. Elliott, Irish Migrants in the Canadas. A New Approach, McGill-Queen's University Press, 1988, p. 245-251.

${ }^{77}$ Ibid., p. 213. Gérard Bouchard n'a sans doute pas raison d'estimer la descendance totale à un niveau aussi élevé qu'au Saguenay. 
average number of different children recorded on three census returns was $7,8 \ldots$ wives of foreign-born husbands tended to bear more children (9) during their childbearing cycle than the wives of second or third generation Canadian men $(6,8) \ldots{ }^{78}$.

Rappelons ici qu'en Nouvelle-France et au Saguenay, la fertilité des couples avait, au contraire, augmenté d'une génération à l'autre à la suite de la migration, alors que, dans le comté de Peel, un processus inverse, particulièrement rapide parmi les jeunes couples, se serait déclenché. Ce qui signifie de la part des femmes, surtout celles des villes, selon Gagan, "a deliberate attempt to limit the size of their families ${ }^{79} \%$. En 1861 , ces différences villes-campagnes, visibles dans toutes les catégories d'âges de 15 à 44 ans, se chiffraient à environ $26 \%^{80}$.

Cette transformation, amorcée avant ou pendant ces moments d'intenses migrations, se poursuit, entre 1851 et 1911 , dans un contexte marqué par un accroissement de l'immigration canadienne-française, par le ralentissement de la croissance démographique dans l'ensemble de la province et par la marche accentuée de l'urbanisation et de l'industrialisation.

En 1791, lorsque le Haut-Canada fut créé, la présence française n'était pas nouvelle sur ce territoire. Non seulement s'était-elle manifestée depuis toujours par des séjours occasionnels ou prolongés de traiteurs, de militaires, d'engagés et de coureurs des bois, mais aussi par des colons établis en permanence autour des postes de traite. Après la cession aux Américains du poste de Détroit, le plus important

${ }^{78}$ David Gagan, Hopeful Travelers. Families, Land, and Social Change in Mid-Victorian Peel County, Canada West, Toronto, UTP, 1981, p. 71. ${ }^{79}$ Ibid., p. 87.

${ }^{80}$ Ibid., p. 131. 
d'entre eux, des colons d'origine française constituèrent des communautés dans les comtés d'Essex et de Kent. Plus tard, vers 1828 , au moment où des francophones arrivaient dans l'est ontarien, d'autres migrants venus du Sud-Ouest et du Bas-Canada se regroupèrent dans le comté de Simcoe.

Mais ce ne fut qu'en 1840 que s'accéléra l'émigration des Canadiens français vers l'Ontario. En moins d'une décennie, leurs effectifs doublèrent et ils se trouvèrent concentrés à peu près également, d'une part, dans le Sud-Ouest et le Centre et, d'autre part, dans l'Est. Dès lors, leur taux de croissance surpassa celui des autres groupes dans toutes les régions de la province où ils étaient installés (tableau 15). Au point qu'en 1911, ils avaient multiplié leurs effectifs 7,5 fois, pendant que les anglophones ne les triplaient même pas. Même si leur pourcentage dans la population augmenta, ils restèrent partout, excepté à quelques endroits, fortement minoritaires, ne représentant en 1911 que 3\% de la population dans le Sud-Ouest et le Centre et $19 \%$ dans l'Est et le Nord.

\section{TABLEAU 15}

Taux moyens annuels de croissance des populations d'origine française et britannique de l'Ontario (1851-1911)

(en pourcentage)

\begin{tabular}{lccc}
\hline & francophone & anglophone & totale \\
population totale & 2,86 & 1,36 & 1,36 \\
Sud-Ouest et Centre & 1,76 & 1,25 & 1,27 \\
Est et Nord & 3,50 & 1,34 & 1,62 \\
Est seul & 2,44 & 0,58 & 0,83 \\
population urbaine totale & 5,13 & 3,50 & 2,73 \\
Sud-Ouest et Centre & 1,88 & 3,42 & 3,45 \\
Est et Nord & 5,90 & 3,91 & 4,44 \\
Est seul & 4,44 & 2,43 & 2,78 \\
\hline
\end{tabular}

Sources: Recensements du Canada. 
Cette avance des francophones venus du Québec et, en certains cas, des Maritimes, faisait donc partie d'un mouvement plus vaste, se propageant à travers l'Outaouais québécois et ontarien et se déplaçant vers le Nord après 1881 . En effet, avec la construction des chemins de fer et la découverte des gisements miniers, leur accès aux terres et aux forêts du nord-ouest québécois et du nord ontarien s'en trouva considérablement facilité. Ainsi, au lieu de suivre le mouvement des habitants d'origine britannique surtout orienté vers le peuplement du sud-ouest et du centre de la province ( $71 \%$ de leurs effectifs y étaient regroupés en 1851 et $73 \%$ en 1911 ), les Ontariens de langue française accrurent leur présence dans l'Est et le Nord, où leurs effectifs, déjà concentrés dans ces régions dans une proportion de $51 \%$ en 1851 , y furent portés à $74 \%$ en 1911 . Pourtant, entre ces univers inégalement occupés par ces deux groupes, que de disparités entre l'un et l'autre en ce qui concerne le revenu de la terre, la densité urbaine, le degré de concentration des industries primaires et manufacturières, le travail rémunéré des femmes mariées et l'accès aux institutions culturelles. Ces immigrants francophones pauvres, encore souvent illettrés et dépendant de leur milieu d'origine, eurentils d'autre choix que d'opter pour le moindre de ces deux mondes?

En se redistribuant ainsi sur l'ensemble du territoire, les migrants francophones eurent tendance, à l'intérieur de chacune des régions, à miser sur certains endroits plutôt que sur d'autres. Dans le SudOuest, en 1911, 85\% d'entre eux étaient regroupés dans Essex-Kent où ils ne constituaient que $22 \%$ de la population. Dans le Centre, un tiers d'entre eux se trouvait dans Simcoe où il ne représentait que $10 \%$ 
de la population. Dans l'Est, quatre sur cinq étaient concentrés dans cinq districts électoraux, incluant la ville d'Ottawa, où ils formaient $43 \%$ de la population. Dans l'ensemble des quatre comtés les plus ruraux de cette région, ils étaient même devenus majoritaires avec $52 \%$ de la population. Dans Prescott, la chose s'était déjà produite en 1871 , au moment où la population d'origine américaine et britannique, arrivée la première, amorçait un long déclin de ses effectifs. Une partie des immigrants qui vinrent alors du Québec, et une portion de la croissance naturelle française de Prescott furent dès lors bien forcées de se diriger, pour une part et pour un temps, vers les comtés voisins de Russell, Stormont et Glengarry. Mais, là aussi, le déclin numérique des Britanniques devint inévitable après 1891 et, à son tour, la population française devint elle-même incapable d'absorber tout le surplus de ses naissances sur ses décès. Au cours des vingt années avant 1911, la population française de ces quatre comtés augmenta de $40 \%$, ce qui était moins que sa croissance naturelle, pendant que les effectifs anglophones baissaient de $15 \%$. Enfin, dans le Nord, récemment ouvert à la colonisation, $85 \%$ des colons d'origine française étaient, en 1911, réunis dans Algoma et Nipissing. Ainsi, l'importance numérique de la minorité ontarienne francophone varia d'une région à une autre, mais, à peu près partout, sa situation, par rapport au milieu ambiant, se ressemblait. Il est vrai qu'elle avait engendré ses propres élites cléricales et laïques appuyées sur de solides institutions, mais elle n'était pas, pour autant, adéquatement représentée parmi les privilégiés de la richesse, du pouvoir et du prestige. En tant que minorité éloignée du pouvoir, décidée à préserver l'intégrité de sa culture, elle ne pouvait, même si elle 
l'avait voulu, résister à des forces aussi puissantes que celles du bilinguisme et de l'urbanisation.

En effet, aux deux villes et villages haut-canadiens de 1000 habitants et plus de 1805, s'en étaient ajoutés 29 autres en 1850 , soit 14 de plus qu'au Québec. Puis, jusqu'en 1911, ce mouvement s'était poursuivi dans les deux provinces et le nombre de ces localités était passé à 174 en Ontario et à 102 au Québec. Ainsi, parti d'un taux d'urbanisation de 5,5\% en 1805, l'Ontario avait si bien dépassé le Québec en 1861, qu'en 1911, la moitié de sa population était urbaine.

Le fait est que les Ontariens d'origine française seront si bien entraînés dans cette direction que, de 1851 à 1911 , leur taux d'urbanisation sera toujours supérieur à celui des Français québécois. En Ontario même, jusqu'en 1871, leur présence dans les agglomérations de 1000 et plus et dans celles de 5000 et plus sera jusqu'à 1871, dans le premier cas, et jusqu'à 1881, dans le second, plus intense que celle des anglophones. Il est vrai que, dans le Sud-Ouest, le Centre et le Nord, ils furent presque toujours plus ruraux que leurs compatriotes anglophones. Mais, dans l'Est, ils furent, au contraire, toujours plus urbains que la population environnante. Cela se comprend bien puisque, au début de la migration, ceux qui furent incapables d'obtenir des terres à leur arrivée, n'eurent d'autres choix que de s'établir, pour un temps ou pour de bon, comme journaliers dans les villages et les villes. Ainsi, pour les Ontariens d'origines diverses, la migration vers Ottawa ou ailleurs constitua toujours une option. 
TABLEAU 16

Taux d'urbanisation des Ontariens d'origine française et britannique dans les villes et villages de I 000 habitants et plus en 1911

(en pourcentage)

\begin{tabular}{lccc}
\hline & $\begin{array}{c}\text { origine française } \\
\text { dans pop. } \\
\text { totale }\end{array}$ & en ville & $\begin{array}{c}\text { britannique } \\
\text { en ville }\end{array}$ \\
Sud-Ouest & $5,4 \%$ & 37,1 & 41,9 \\
Essex-Kent & $21,6 \%$ & 37,1 & 46,0 \\
Centre & $1,8 \%$ & 63,2 & 64,1 \\
Simcoe & $8,0 \%$ & 44,0 & 42,3 \\
Est & $20,0 \%$ & 49,2 & 42,4 \\
cinq districts électoraux* * & $43,4 \%$ & 48,2 & 59,8 \\
quatre comtés** & $51,9 \%$ & 28,5 & 21,9 \\
Nord & $18,5 \%$ & 36,6 & 41,9 \\
Algoma-Nipissing & $27,5 \%$ & 34,8 & 55,2 \\
province & $8,0 \%$ & 38,4 & 55,2 \\
\hline
\end{tabular}

Source: Recensement du Canada, 1911. *Ottawa, Prescott, Russell, Glengarry, Stormont; * district électoral d'Ottawa exclu.

Autant la population d'appartenance française urbaine était concentrée dans l'Est et le Nord: $68 \%$ en 1851 et $83 \%$ en 1911 , autant leurs concitoyens l'étaient dans le sud-ouest et le centre de la province: $73 \%$ en 1851 et $79 \%$ en 1851 . Autant Toronto, une ville de 327753 habitants en 1911, était la capitale des habitants d'origine britannique, autant Ottawa, avec ses 73193 habitants, était celle des Ontariens d'origine française, même si ces derniers n'y représentaient que $30 \%$ de la population.

Nul ne saurait nier la complexité de ces profils ethniques, linguistiques, régionaux, urbains et sociaux qui se reflètent dans la diversité des comportements démographiques ${ }^{81}$.

${ }^{81}$ Ouellet, "Évolution de la présence francophone en Ontario: une perspective économique et sociale», C. Jaenen (dir.), Les FrancoOntariens, Ottawa, PUO, 1993, p. 127-199; Gaétan Gervais, «L'Ontario français, 1821-1910», ibid., p. 49-125. 
Comme ces francophones arrivaient à peine du Québec et des Maritimes, leur comportement démographique reproduisit pendant un certain temps celui de leur milieu d'origine. Étant catholiques, leurs alliances avec les anglophones protestants et même catholiques furent rarissimes. Celles-ci furent cependant beaucoup moins fréquentes parmi eux qu'elles ne le furent parmi les anglophones. Comme la société traditionnelle canadienne-française incitait, entre autres, les filles à se marier jeunes, elles eurent plus d'enfants en moyenne que celles venues des Îles Britanniques. Pourtant, de 1851 à 1871 , à Alfred et Caledonia, dit Gaffield, elles n'eurent qu'un enfant de plus que les autres parce qu'elles convolèrent plus jeunes $^{82}$. Celui-ci ajoute même que la dimension des familles diminua dans les deux groupes entre 1851 et $1881^{83}$. Ce qui veut dire, si on en croit Gaffield, que ces familles, contrairement à celles qui partirent de Charlevoix vers le Saguenay, auraient presque spontanément remis en question la tradition et pratiqué un certain contrôle des naissances. Si ce changement, bien inusité, fut aussi rapide et uniforme qu'il le dit, comment peut-on expliquer qu'en 1941 les Franco-Ontariennes rurales mariées, âgées de 45 à 54 ans, auraient été, selon les chiffres d'Enid Charles tirés du recensement, plus fertiles que leurs ancêtres de Prescott des années 1850 (7,7 enfants contre 7,2), et que l'écart entre elles et les anglophones protestantes ait alors été de quatre enfants? Le même problème se pose, si on se reporte au recensement de 1961. Car, à cette date, les Franco-Ontariennes vivant sur une ferme, âgées de 65 ans et plus auraient

${ }^{82}$ Chad Gaffield, Aux origines de l'identité franco-ontarienne, Ottawa, PUO, 1993, p. 70-73.

${ }^{83}$ Ibid., p. 79. 
eu autant d'enfants que les rurales de même origine du milieu du XIX ${ }^{e}$ siècle $(7,3$ contre 7,2$)$. Bien plus, l'écart entre elles et les anglophones, quoique réduit depuis 1941, aurait encore été 3,53 fois plus élevé qu'il ne l'était un siècle plus tôt. Cette analyse de Gaffield ne cadre pas non plus avec le fait qu'à Moonbeam, entre 1919 et 1922 , la natalité canadienne-française moyenne, bien que substantiellement plus basse qu'au Saguenay à la même époque, se tenait encore, selon Michel D'Amours, à $4,30 \%^{84}$. Pas plus d'ailleurs qu'elle n'explique qu'entre 1901 et 1941, dans la paroisse rurale Saint-Joseph, près de Sudbury, étudiée par Donald Dennie, le taux moyen de fécondité légitime, était encore le double de celui de la population à dominance canadiennefrançaise de la paroisse urbaine de Sainte-Anne de Sudbury et de l'ensemble de l'Ontario rural et urbain. Ce taux surpassait aussi, par une marge de $20 \%$, celui du Québec rural et urbain. Il va de soi qu'en s'abaissant de $32 \%$ pendant ces quatre décennies, la fécondité a suivi à Saint-Joseph un parcours parallèle à celui du reste de la province ${ }^{85}$. Tout cela ne confirme-t-il pas, au contraire, le fait que les Canadiens français de l'Ontario, comme ceux du Québec et des Maritimes, tout en arrivant progressivement à la suite des autres, à pratiquer un certain contrôle sur les naissances, mais beaucoup plus tard que ne le dit Gaffield, auraient là aussi, selon la formule de Jacques Henripin, opposé une "résistance remarquable à la diminution de la fécondité observée dans les pays industrialisés»?

s4 «Etude socioéconomique d'une communauté francophone du nordest ontarien", thèse de M.A., Université d'Ottawa, 1985, p. 43.

${ }^{85}$ Donald Dennie, "Le Comportement démographique de deux paroisses canadiennes-françaises de la région de Sudbury», Revue du NouvelOntario, 16, 1994, p. 9-39. 
TABLEAU 17

Nombre moyen d'enfants en 1941 des femmes mariées de 45 à 54 ans chez les francophones catholiques et les anglophones protestants

\begin{tabular}{|c|c|c|c|c|}
\hline \multirow[b]{2}{*}{$\begin{array}{c}\text { nés: } \\
\text { Scolarité } 0-8 \text { ans }\end{array}$} & \multicolumn{2}{|c|}{$\begin{array}{l}\text { francophones } \\
\text { catholiques }\end{array}$} & \multicolumn{2}{|c|}{$\begin{array}{l}\text { anglophones } \\
\text { protestants }\end{array}$} \\
\hline & sur ferme & en ville & sur ferme & en ville \\
\hline Maritimes & 7,80 & 6,20 & 4,99 & 3,74 \\
\hline Québec & 8,53 & 5,47 & 3,81 & 2,96 \\
\hline $\begin{array}{l}\text { Ontario } \\
\text { scolarité } 9-12 \text { ans }\end{array}$ & 7,66 & 5,46 & 3,61 & 2,76 \\
\hline Maritimes & 6,45 & 3,45 & 3,80 & 2,46 \\
\hline Québec & 7,66 & 4,33 & 3,17 & 1,96 \\
\hline Ontario & 6,73 & 4,48 & 2,87 & 2,08 \\
\hline
\end{tabular}

Source: Enid Charles, Changing Size of the Family in Canada, Census Monograph, No 1, 1941, Ottawa, Edmond Cloutier, 1948, p. 72, 73.

Enid Charles mentionne un déclin de $13 \%$ de la fécondité au Canada entre 1898 et 1921 et de $33 \%$ du taux brut de reproduction de 1921 à 1941. Les francophones y participèrent, mais sans doute moins que les autres, puisque, après une analyse exhaustive des données du recensement de 1941, Charles présenta les familles rurales francophones du Nouveau-Brunswick et du Québec et celles des villes à prédominance francophone comme des foyers de haute natalité. À leur suite dans la même catégorie, venaient les Franco-Ontariennes. Ce fait est, d'ailleurs, confirmé par les statistiques vitales de 1921. En effet, la natalité des Acadiens du NouveauBrunwick, alors plus élevée que celle de leurs compatriotes de la Nouvelle-Écosse et de l'îledu-Prince-Édouard, se montait à $4 \%$ pendant que celle de leurs équivalents francophones de l'Ontario ne dépassait pas les $3,27 \%$. Il avait aussi constaté que les ouvriers non qualifiés du secteur primaire, catégories dans lesquelles les francophones étaient toujours 
DÉMOGRAPHIE DES COMMUNAUTÉS FRANCOPHONES

et à peu près partout surreprésentés en 1941, constituaient des classes plus prolifiques que les groupes plus instruits et fortunés ${ }^{86}$.

Si les données sur les mariages, les naissances et les décès incluses dans les registres des confessions religieuses avaient été compilées, comme elles l'ont été au Québec, il serait plus facile de regarder les recensements du XIX ${ }^{\mathrm{e}}$ siècle avec un œil critique. À défaut d'un tel instrument permettant d'élaborer des séries continues, il faut bien, pour obtenir ce résultat, s'en remettre à d'autres sources. Il est vrai qu'en 1868 le gouvernement ontarien avait passé une législation pour l'enregistrement des actes de l'état civil et la collecte des statistiques vitales. Mais, dès le départ, les chiffres transmis par les officiers locaux sur les naissances étaient fort au-dessous de ceux des recensements: une marge de $50 \%$ en 1871 , progressivement réduite à $8 \%$ en 1901 . Cette amélioration fut sans doute attribuable à la nomination d'un inspecteur en 1871, dont l'autorité fut appuyée par trois lois successives. Les remarques de l'inspecteur sont donc importantes puisqu'elles permettent de tester les chiffres globaux inscrits dans les recensements.

Nous savons déjà que les données sur la mortalité sont les plus sous-représentées dans les recensements non seulement au Québec et dans les Maritimes, mais aussi en Ontario. À preuve, la montée brutale et énorme, inexplicable sans cela, de l'ensemble des décès et de ceux des enfants de moins d'un an entre 1861 et 1871 dans les deux provinces (tableau 19). D'ailleurs, de 1871 à 1901 , le problème n'est pas résolu, puisque le nombre des sépultures augmente quand même beaucoup plus rapidement dans

${ }^{86}$ Charles, op. cit., p. 93, 102. 
TABLEAU 18

Nombre de naissances et taux corrigés de natalité faits à partir de nos estimations et de celles suggérées par l'inspecteur des données vitales pour l'Ontario 1851-1931

(taux en pourcentage)

\begin{tabular}{lccccccccc}
\hline \multicolumn{4}{c}{ Ontario } & \multicolumn{5}{c}{ Québec } \\
& \multicolumn{4}{c}{ recensements } & \multicolumn{2}{c}{ estimations } & \multicolumn{2}{c}{ recensements } & \multicolumn{2}{c}{ estimations } \\
1851 & 32681 & 3,53 & $36000^{*}$ & 3,89 & 36719 & 4,12 & & \\
1861 & 52394 & 3,82 & & & 40767 & 3,67 & $43000^{*}$ & 3,87 \\
1871 & 50051 & 3,10 & $56700^{* *}$ & 3,52 & 45813 & 3,84 & & \\
1881 & 55891 & 2,93 & $63424^{* *}$ &, 33 & 53018 & 3,90 & & \\
1891 & & & $67131^{* *}$ & 3,17 & 59038 & 3,97 & \\
1901 & 49448 & 2,48 & $56601^{* *}$ & 2,59 & 58651 & 3,56 & \\
1911 & & & $70120^{* *}$ & 2,78 & 71376 & 3,56 & \\
1921 & 74152 & 2,52 & & & & & & \\
1931 & 69209 & 2,02 & & & 83606 & 2,91 & & \\
& & & & & & & & \\
\end{tabular}

Sources: Recensements du Canada; R. Kuczynski, op.cit., p. 104-110. *nos estimations, ** celles de l'inspecteur

les deux provinces que la population: $35 \%$ pour la population et $99 \%$ pour les décès en Ontario; $24 \%$ pour la population et $46 \%$ pour les décès globaux au Québec. Bien entendu, on ne saurait partir d'une succession de données inégalement rapportées aux recenseurs et prétendre y lire clairement, même pour la mortalité infantile, l'impact négatif des conditions créées par l'urbanisation et l'industrialisation des années 1850 à 1900 .

Ces lacunes n'empêchent cependant pas chacun de ces recensements de reproduire des polarisations qui, en gros, sont les mêmes dans toutes les régions de l'est du Canada. Ainsi, les écarts qui se dégagent de ces recensements entre l'Ontario et le Québec, en ce qui concerne la natalité et la mortalité (tableaux 18 et 19), ne sont pas limités à ces deux provinces. Car ils tiennent aux multiples interactions entre les cultures, les niveaux d'instruction, les régions, les 
DÉMOGRAPHIE DES COMMUNAUTÉS FRANCOPHONES

TABLEAU 19

La mortalité générale et infantile en Ontario et au Québec selon les recensements (1851-1931)

(taux en pourcentage)

\begin{tabular}{|c|c|c|c|c|c|c|c|c|}
\hline & \multicolumn{4}{|c|}{ Ontario } & \multicolumn{4}{|c|}{ Québec } \\
\hline & \multicolumn{2}{|c|}{ m. générale } & \multicolumn{2}{|c|}{ m. infantile } & \multicolumn{2}{|c|}{ m. générale } & \multicolumn{2}{|c|}{ m. infantile } \\
\hline & nbre & taux & nbre & taux & nbre & taux & nbre & taux \\
\hline 1851 & 7736 & 0,83 & 1959 & 6,0 & 10769 & 1,21 & 3421 & 9,3 \\
\hline 1861 & 9993 & 0,73 & 2472 & 4,7 & 12839 & 1,15 & 4226 & 10,4 \\
\hline 1871 & 17958 & 1,11 & 4246 & 8,5 & 20813 & 1,75 & 7529 & 16,4 \\
\hline 1881 & 22937 & 1,20 & 5485 & 9,8 & 26074 & 1,92 & 8263 & 15,6 \\
\hline 1891 & 24009 & 1,13 & 5661 & & 28480 & 1,91 & 10448 & \\
\hline 1901 & 30526 & 1,40 & 6820 & 14,2 & 30410 & 1,84 & 13100 & 22,3 \\
\hline 1931 & 35765 & 1,04 & 4833 & 9,8 & 30487 & 1,87 & 9443 & 11,3 \\
\hline
\end{tabular}

Sources: Recensements du Canada.

rapports villes-campagnes et les situations économiques prévalant dans chaque région. Ainsi, en Ontario, aussi bien à l'échelle de ses quatre grandes régions qu'à celle de la province, des contrastes existent, comme au Québec et dans les Maritimes, au plan de la mortalité entre les francophones et les protestants. À peu près partout, excepté dans le comté de Nipissing où les anglophones catholiques et protestants étaient beaucoup plus présents que les francophones en milieu urbain et dans les mines, les francophones eurent des taux de mortalité supérieurs à ceux des protestants. Comme les Franco-Ontariens représentaient partout une fraction variable des catholiques, leurs taux de mortalité, bien qu'identiques au niveau provincial à ceux des autres catholiques, en différaient cependant au niveau régional. Tandis que les taux francophones étaient plus élevés dans l'Est et le Nord, ceux des autres catholiques l'emportaient dans le Sud-Ouest et le Centre. Néanmoins, dans les comtés de Prescott et de Russell, les anglophones catholiques, groupe en déclin, vieillissant et plus rural que 
la communauté francophone, étaient plus sujets à la maladie et à la mort que les francophones. À Ottawa, au contraire, la mortalité des francophones, plus considérable que celle des catholiques anglophones, reflétait, au moins en partie, leur statut socioéconomique inférieur. Notons enfin que, plus les francophones étaient concentrés dans une région particulière, plus la mortalité infantile était importante (tableau 20). Ainsi, entre 1891 et 1941, dans la région de Sudbury, à Saint-Joseph et à Sainte-Anne, l'indice de mortalité infantile était-il de 122 dans le premier cas et de 158 dans le second par rapport à celui de l'Ontario ${ }^{87}$.

\section{TABLEAU 20}

La mortalité générale des habitants (1) d'origine française, (2) des catholiques, (3) des Britanniques, (4) des protestants, (5) la mortalité générale et (6) infantile en Ontario en 1901 (taux en pourcentage)

\begin{tabular}{lccccccr}
\hline & $(1)$ & $(2)$ & $(3)$ & $(4)$ & $(5)$ & $(6)$ & $(7 \cdot)$ \\
Sud-Ouest & 1,54 & 1,99 & 1,35 & 1,30 & 1,36 & 12,2 & 4,8 \\
Essex-Nord & 1,75 & 1,68 & 1,39 & 1,38 & 1,53 & 15,7 & 38,9 \\
Centre & 1,46 & 1,85 & 1,56 & 1,52 & 1,56 & 14,7 & 1,8 \\
Est & 2,08 & 1,98 & 1,40 & 1,30 & 1,52 & 14,5 & 17,7 \\
Presc.-Russell & 1,92 & 2,13 & 1,71 & 1,21 & 1,83 & 20,5 & $59,0 \ldots$ \\
Ottawa & 2,87 & 2,56 & 1,68 & 1,52 & 2,07 & 20,9 & 33,0 \\
Nord & 1,81 & 1,55 & 1,66 & 1,75 & 1,69 & 16,8 & 16,5 \\
Nipissing & 1,63 & 1,68 & 1,94 & 2,01 & 1,81 & 18,0 & 42,1 \\
Province & 1,87 & 1,87 & 1,48 & 1,42 & 1,50 & 14,2 & 6,7 \\
c. franco. & 2,05 & 2,09 & 1,30 & 0,98 & 1,63 & 19,4 & $40,2 \ldots$ \\
& & & & & & &
\end{tabular}

Sources: Recensement du Canada, 1901.* pourcentage de francophones; ${ }^{* *}$ Ottawa, Prescott, Russell; ${ }^{* * *}$ les comtés mentionnés dans ce tableau.

Comme nous l'avons signalé à maintes reprises à propos des Maritimes et du Québec, ces disparités, culturelles pour une bonne part, furent aussi

${ }^{87}$ Dennie, op. cit., p. 34. 
attribuables au contact avec la ville et aux types d'occupations dans lesquelles les personnes étaient concentrées. En effet, les conditions de vie dans les villes contribuèrent partout à y infléchir la natalité et à y stimuler la mortalité générale et infantile. Mais elles le firent d'une façon inégale dans chacun des groupes linguistiques et dans chacune des régions. Comme ces différences villes-campagnes remontaient au XVII ${ }^{\mathrm{e}}$ siècle dans le Canada-Est, on ne devrait pas s'étonner de découvrir qu'elles soient devenues identifiables, en tout ou en partie vers 1851 , dans dix-huit villes de la jeune colonie du Canada-Ouest alors en formation accélérée. Au Québec, les taux de natalité et de mortalité urbains reflétaient ceux d'une province à très forte majorité française et catholique engagée presque soudainement dans la première étape de l'urbanisation et de l'industrialisation, alors que ceux de l'Ontario étaient ceux d'une province à grande majorité anglophone et protestante en voie de s'urbaniser et de s'industrialiser progressivement. Aussi les taux ontariens étaient-ils pour ces raisons et pour d'autres, parfois par une marge très substantielle, dans le cas de la mortalité générale et infantile, inférieurs à ceux du Québec (tableau 21).

Envisagé dans ce contexte, le comportement démographique des Franco-Ontariens nous a semblé davantage apparenté à celui des Québécois francophones et des Acadiens qu'à celui des autres Ontariens. Autant ils se sont ajustés à leur façon aux conditions physiques et économiques prévalant dans les lieux où ils étaient regroupés, autant ils semblent avoir résisté, mais avec moins de succès que leurs compatriotes du Québec et du Nouveau-Brunswick, aux forces qui appelaient une modernisation des comportements démographiques (voir tableaux 1 et 17). 


\section{TABLEAU 21}

Taux de natalité, de mortalité et de mortalité infantile: différences villes-campagnes en Ontario et, à cet égard, disparités Ontario-Québec

(en pourcentage)

\begin{tabular}{rcccccc}
\hline & \multicolumn{2}{c}{ natalité } & \multicolumn{2}{c}{ mortalité } & \multicolumn{2}{c}{ m. Infantile } \\
& v./camp & Ont./Qué. & v./camp. Ont./Qué. & v./camp. & Ont./Qué. \\
1851 & 93 & 85 & 186 & 77 & 290 & 61 \\
1861 & 98 & 97 & 191 & 65 & 225 & 41 \\
1871 & 87 & 73 & 142 & 60 & 176 & 49 \\
1881 & 102 & 76 & 121 & 56 & 128 & 56 \\
1891 & & & 124 & 63 & & \\
1901 & 79 & 82 & 150 & 97 & 174 & 68 \\
\hline
\end{tabular}

Sources: Recensements du Canada.* les villes ontariennes retenues pour ces calculs sont London, Hamilton, Toronto, Kingston, Brockville et Ottawa; les villes québécoises choisies pour la comparaison avec l'Ontario sont Montréal et Québec.

Même si, dans le tableau 22, les écarts entre les Franco-Ontariens et les autres Ontariens en ce qui concerne la natalité et les mortalités paraissent s'élargir, on ne saurait, vu les déficiences des recensements, nier l'existence d'une tendance vers le contrôle volontaire des naissances et un abaissement de la mortalité infantile.

\section{TABLEAU 22}

Taux de natalité, de mortalité générale et de mortalité infantile en Ontario: disparités entre comtés dits français et des comtés dits britanniques (1851-1901)

(en pourcentage)

\begin{tabular}{lccc}
\hline & $\begin{array}{c}\text { natalité } \\
\text { c. fr.c. angl. }\end{array}$ & $\begin{array}{c}\text { mortalité générale } \\
\text { c. fr/c. angl. }\end{array}$ & $\begin{array}{c}\text { m. infantile } \\
\text { c. fr./c. angl. }\end{array}$ \\
1851 & 110 & 95 & 92 \\
1861 & 105 & 104 & 137 \\
1871 & 113 & 132 & 126 \\
1881 & 122 & 125 & 121 \\
1891 & & 135 & \\
1901 & 141 & 109 & 138 \\
1931 & 140 & 98 & 136
\end{tabular}

Sources: Recensements du Canada. 
Le fait demeure que l'écart observé dans les Maritimes et au Québec, entre les régions à plus grande concentration anglophone et celles à plus fort regroupement francophone, existe aussi en Ontario.

\section{Conclusion}

Mourir hier et aujourd'hui est un livre dans lequel Serge Gagnon s'emploie à dénoncer, à qui mieux mieux, l'hédonisme, la révolution sexuelle, le contrôle des naissances, l'avortement et, dans la même foulée, le non au référendum de 1980 . C'est à partir de cette remise en question sans nuance des temps présents, faite au nom de la tradition catholique la plus rigide en faveur de la transmission, soi-disant généreuse, de la vie, qu'il en arrive à présenter les migrations des Canadiens français du XIX ${ }^{e}$ siècle vers les régions périphériques du Québec et vers les États-Unis comme une fuite en avant destinée à les sauver collectivement du spectre de la contraception:

Dans le Québec du XIX ${ }^{e}$ siècle, on a continué à donner la vie, malgré la pauvreté, malgré les inévitables migrations des surnuméraires vers les nouveaux terroirs au climat rigoureux, aux terres infertiles, malgré l'exil inévitable vers la Nouvelle-Angleterre. Les Canadiens français d'alors croyaient l'expatriation préférable au recours à la contraception massive dont ils connaissaient cependant les secrets... La survie de la collectivité était alors garantie par un usage mesuré des plaisirs du lit. Cette retransmission pléthorique de la vie humaine assurait le triomphe de la vie sur la mort ${ }^{88}$.

Cette analyse que ne renierait pas un tenant de l'idéologie Pro-Vie, va loin, puisque «la mort pléthorique des enfants», "un ange acquis au ciel», selon

${ }^{88}$ Serge Gagnon, Mourir hier et ajourd'hui, Québec, PUL, 1987, p. 166s.; "Morales d'aujourd'hui, morales d'hier», Benoit Lacroix et Jean Simard, Religion populaire, religion de clercs?, Québec, IQRC, 1984, p. 79-94. 
les anciens, lui apparaît même comme un juste prix à payer pour la survie d'une collectivité nationale catholique érigée sur le principe de la sélection naturelle ${ }^{89}$. Évidemment, Gagnon ne se préoccupe pas tellement de l'ampleur exceptionnelle de la mortalité infantile aussi bien chez ceux qui partirent que chez ceux qui restèrent.

Il est vrai que les colons français du XVII siècle avaient voulu engendrer de vrais chrétiens en suivant de près les règles de l'Église sur la fécondité des couples. Mais cela ne signifie pas que, si les pionniers canadiens eurent plus d'enfants que les catholiques de France et que si leurs descendants immédiats en eurent plus qu'eux, ce fut uniquement parce que le clergé de la Contre-Réforme, venu au pays, avait une confiance illimitée dans les forces de la nature et qu'il veillait au grain. À vrai dire, ce fut aussi parce que la famille était, particulièrement en pays neuf, l'unité économique de base, qu'on eut aussi besoin d'une main-d'œuvre nombreuse pour faire les défrichements, cultiver le sol et participer, sur une base saisonnière, soit à la pêche, soit à la traite des pelleteries, soit, plus tard, à l'exploitation de la forêt. Si cette tendance vers l'accroissement de la natalité se manifesta jusqu'à la décennie 1840-1850, il faut, en plus, l'attribuer à l'augmentation plus rapide de la population des campagnes qu'à celle des villes et au déclin de l'alphabétisme, surtout en dehors des villes, ces centres de diversification sociale, d'éducation et de changement démographique. Car, déjà au XVII ${ }^{e}$ siècle, le nombre d'enfants par famille y était moindre et la mortalité plus vigoureuse qu'en milieu rural.

${ }^{89}$ Gagnon, ibid., p. 14. À l'appui de ses sentiments, il cite les propos désabusés de Freud justifiant la mortalité infantile. 
Des niveaux aussi élevés de fécondité, maintenus pendant deux siècles, n'allaient pas sans une forte mortalité générale, féminine et infantile. Au XVII siècle, en l'absence de toute pression sur la terre, la mortalité resta relativement modérée comparée à celle qui prévalait en France. Mais, à mesure que progressa le peuplement, que la société devint plus structurée, que des terroirs, en nombre croissant, devinrent saturés et que s'installa la pauvreté, la mortalité se comporta davantage comme elle le faisait dans des sociétés plus anciennes. La colonie n'échappa pas non plus à des événements dramatiques dont la conséquence était de mousser subitement la mortalité, de retarder les mariages et d'abaisser la natalité. Les épidémies assez fréquentes, parfois très sévères, les mauvaises récoltes, les guerres et, parfois, les trois ensemble, provoquèrent des sursauts de mortalité qui, le plus souvent, secouèrent vivement les habitants sur le coup, mais eurent d'autant moins d'effets durables à certains égards qu'on les présenta à la population comme des punitions divines.

Ce ne fut qu'après 1850 que débuta le déclin à long terme de la nuptialité, de la natalité et de la mortalité parmi les catholiques francophones. Cette mutation qu'on pourrait identifier, si on n'y faisait attention, avec le début ferme du contrôle volontaire des naissances, eut d'abord son origine dans le mouvement de saturation des vieux terroirs seigneuriaux et la diffusion accrue de la pauvreté qui s'engagea au début du XIX' siècle. Car la pénurie de bonnes terres aisément accessibles déclencha la constitution d'un prolétariat rural en mal de terres et d'emplois, sorte de prélude à la migration vers d'autres lieux. 
Ces surplus démographiques, constitués de jeunes couples et de célibataires, se dirigèrent d'abord vers les régions périphériques et provoquèrent l'ouverture de nouvelles régions à la colonisation agricole et à l'exploitation forestière. Ce fut le cas du SaguenayLac-Saint-Jean, du Bas-Saint-Laurent et du HautSaint-Maurice. D'autres empruntèrent la voie qui conduisit à la reconquête de régions où les anglophones avaient jusque-là dominé: la Gaspésie, les cantons de l'Est et l'Outaouais québécois. Dans tous les cas, la phase pionnière donna lieu à une baisse temporaire de la mortalité mais, nulle part, elle n'entraîna une chute immédiate de la natalité. Le Saguenay, plus encore que le Bas-Saint-Laurent, fut exemplaire à cet égard, car les colons y refirent si bien l'expérience des pionniers de la Nouvelle-France que la natalité non seulement augmenta, mais n'y descendit audessous de $5 \%$ qu'après 1930 . Dans les régions où anglophones et francophones se côtoyaient, chacun $\mathrm{y}$ resta fidèle à sa tradition. Le canton de Winslow est typique à cet égard: la fécondité des Canadiennes françaises y était supérieure à celle des Écossaises qui, entre 1850 et 1880 , pratiquaient, écrit John Little, une forme de contrôle des naissances.

En vérité, la chute des facteurs de la croissance naturelle chez les francophones québécois s'explique bien davantage par leur émigration vers les ÉtatsUnis et le Haut-Canada: un exode net qu'on peut estimer à environ 560000 personnes de 1851 à 1911 . Ce mouvement massif de jeunes couples et de célibataires affecta la nuptialité à la baisse, se répercuta ensuite sur la natalité et, à un moindre degré, sur la mortalité, modifiant ainsi la structure des âges dans la population en place. 
L'urbanisation et l'industrialisation, amorcées vers 1850 , auraient pu transformer rapidement le régime démographique par le simple fait du reclassement progressif des hommes et des femmes dans de nouvelles occupations, les unes étant moins propices à la haute natalité que les autres et présentant plus de risques de maladie et de mortalité que les autres. N'oublions pas cependant que l'exode des ruraux vers les villes ne modifia pas sur le champ des croyances et des comportements qui, depuis toujours, assuraient la haute natalité et qui, en ville, tendaient à aggraver parmi eux la mortalité générale et infantile. D'autant plus, en ce qui concerne la natalité, que le travail en usine des femmes mariées était encore marginal et que les Canadiens français étaient généralement moins instruits et surreprésentés dans les occupations les plus susceptibles de maintenir cette situation. Si les villes, en particulier Montréal, furent des lieux privilégiés pour l'éclosion du contrôle volontaire des naissances, cette tendance, à peine esquissée auparavant, ne se précisa vraiment qu'au tournant du siècle. Parmi les facteurs de longue durée susceptibles de tempérer la diffusion de ces pratiques qui interpellaient de toutes sortes de façons la tradition au nom de l'autonomie de la personne, il faut, bien sûr, tenir compte de la croissance extraordinaire du contrôle clérical sur les consciences et les institutions, en particulier sur l'éducation prise en charge par les prêtres séculiers, les religieux et les religieuses. On ne saurait, à ce sujet, sous-estimer l'impact de ces pouvoirs exercés, au surcroît, par le biais des prédications et des confessions. À propos des cohortes de femmes qui s'étaient mariées pour la première fois entre 1932 et 1958, Danielle Gauvreau et Peter Gossage affirment que les «catholiques ont 
$36 \%$ moins de chances d'utiliser la contraception que les non-catholiques ${ }^{90}$ \%.

Les différenciations entre les groupes ethniques et religieux, quant à la natalité et à la mortalité, débutèrent à la Conquête. Les premiers immigrants anglophones étaient protestants en grande majorité, très souvent célibataires, comme cela était arrivé en Nouvelle-France au XVII ${ }^{\mathrm{e}}$ siècle, et ils appartenaient à des catégories sociales plus instruites que l'ensemble de la population locale. Enfin, ils étaient, en très grande majorité, concentrés dans les villes où ils dominaient économiquement et politiquement. Il va de soi que, sans être identique à celui des élites francophones urbaines, leur profil démographique était cependant éloigné de celui de la masse de la population.

Plus tard, à la suite des vagues loyalistes et de l'immigration, de plus en plus massive, venue des Îles Britanniques, la composition de la population anglophone changea radicalement. Parmi ces immigrants, les familles l'emportaient largement sur les célibataires, alors que les éléments populaires, à la fois attirés par les terres disponibles dans les cantons et désireux d'avoir accès aux emplois urbains et ruraux, surclassaient numériquement les élites par une marge énorme. Cette immigration nouvelle, faite d'éléments plus instruits que la population locale, contribua donc à la mise en place d'une population encore plus diversifiée sur les plans religieux et social et répartie différemment d'autrefois entre les villes et les campagnes. En 1850, non seulement avait-elle

${ }_{90}$ Danielle Gauvreau et Peter Gossage, «Empêcher la famille. Fécondité et contraception au Québec», Canadian Historical Review, 78, 1997, p. 500. 
révolutionné en milieu urbain l'équilibre entre les classes et celui entre les groupes ethniques, mais elle avait porté la présence des anglophones dans les campagnes à $75 \%$ de leurs effectifs. Et, pourtant, tout cela n'avait pas éliminé les différences entre les francophones et les autres au plan de la natalité et de la mortalité.

Comme ces groupes ethniques et religieux étaient culturellement partagés et inégalement concentrés sur le territoire québécois à ces divers points de vue, leur profil démographique, tout en évoluant dans la même direction que celui des autres sous l'influence de certaines forces communes, varia néanmoins d'un groupe à l'autre. Ces distinctions quant aux niveaux de natalité et de mortalité départageaient non seulement les anglophones catholiques et protestants entre eux, mais aussi les diverses confessions protestantes entre elles. Bien plus, entre tous ces groupes et les francophones catholiques, les contrastes étaient encore plus marqués qu'entre chacun de ces groupes. Car, aux différences culturelles, s'ajoutèrent celles qui existaient en ce qui concerne le rapport à la ville, spécialement le degré de concentration dans la ville de Montréal et sa région, ainsi que l'intensité différente de leur présence dans les catégories socioprofessionnelles les plus exigeantes du point de vue instruction et les plus accueillantes pour les enfants des familles riches. Ce sont précisément ces clivages que Enid Charles et Jacques Henripin exhumèrent en 1948 et en 1961, le premier quant à la fécondité des couples au Canada en 1941, et le second quant à la mortalité à Montréal entre 1926 et 1958.

Si les Acadiens n'avaient eu leurs propres circonstances, notamment le contact continu avec la mer, 
leur expérience aurait été une reproduction à peu près fidèle de celle des Québécois francophones. Mais, colonie négligée de la France, l'Acadie eut une existence encore plus menacée de l'extérieur que la Nouvelle-France. Avec celle-ci, ses rapports en étaient de dépendance, mais aussi d'autonomie. Ainsi, faute d'appuis de la part de la métropole et de contacts suffisants avec l'économie nord-atlantique, ses effectifs restèrent minuscules jusqu'au jour où elle devint possession anglaise en 1713: moins de 400 habitants en 1671 , environ 600 en 1686 et un peu plus de 2500 en 1714.

Bien que petite en nombre, l'immigration avait néanmoins été un facteur, plus important qu'on ne l'a dit, de sa croissance démographique. Elle le resta d'autant plus par la suite que la rivalité commerciale et militaire franco-anglaise s'intensifia dans la région. L'émergence d'une Acadie française, bien fortifiée pour résister aux Anglais, annexée aux pêcheries internationales et impliquée dans les échanges avec la France, les Indes occidentales et, même, avec la Nouvelle-Angleterre, donna un élan à l'économie, à l'immigration et à la diversification sociale. L'Acadie anglaise, dont l'agriculture était axée sur l'élevage, bénéficia considérablement de cette recrudescence d'activités. La croissance de la population d'origine française, bien que substantielle, y fut néanmoins freinée par le déclin de l'apport migratoire et par les départs vers l'autre Acadie. D'ailleurs, dès le XVII ${ }^{e}$ siècle, Port-Royal était devenu un foyer de migrations vers l'intérieur qui, plus tard, débordèrent en Acadie française.

En somme, des univers relativement diversifiés socialement et assez prospères, dont la démographie, du 
moins celle de Port-Royal décrite par Gisa Hynes, ressemblait fort à celle de la Nouvelle-France. Les femmes s'y mariaient jeunes et avaient un nombre d'enfants équivalent à celui des familles de la vallée du Saint-Laurent. Aussi la mortalité différait-elle peu de celle de l'autre colonie française.

Brisée par la déportation et l'errance de ceux qui avaient échappé à cette calamité, les survivants entreprirent après 1763 , avec le concours de ceux qui revinrent peu à peu, de reconstituer leur société sur un territoire ouvert depuis 1748 à l'immigration britannique. Évidemment, ils ne récupérèrent pas leurs anciennes assises foncières. Mais, œuvrant en silence pendant le siècle suivant, ils remirent sur pied leur économie, combinant fort souvent l'agriculture, la pêche et les activités forestières, et leur structure sociale, appuyée sur un réseau institutionnel encore rudimentaire, commença à se diversifier. Le territoire, où ils vivaient en minorité, fut divisé en trois provinces. Avec le temps, au lieu de se concentrer de plus en plus en Nouvelle-Écosse, une proportion croissante des jeunes couples se déplaça vers le Nouveau-Brunswick où il était plus facile d'avoir accès à la terre. Dans chacune de ces provinces, ils se rassemblèrent dans certaines régions plutôt que dans les autres. Ceci dit, vers 1850, ils constituaient partout des minorités aux pourcentages variables, toujours sans force politique.

Donc, pour les Acadiens comme pour les autres habitants, l'immigration fut alors un facteur important de la croissance démographique. Les études font défaut pour documenter les taux de nuptialité, de natalité et de mortalité d'alors, mais, sachant ce qu'il en est après 1850 , on ne saurait nier que le profil 


\section{Fernand Ouellet}

démographique acadien eut de grandes similitudes avec celui des francophones du Québec à la même époque: celui d'une population catholique pauvre, encore peu instruite, surreprésentée dans les activités primaires et dans les occupations les moins rémunératrices et prestigieuses. À cette exception, toutefois, que leurs taux de natalité et de mortalité furent plus bas que les taux québécois.

À leur côté, se trouvait une population anglophone également enrichie par l'immigration et diversifiée sur les plans ethnique, religieux et social. Dans ses rangs, se trouvaient des groupes ethniques et religieux et des classes sociales désavantagées. Il n'en reste pas moins que, dans l'ensemble, cette majorité, unie par la langue, bien que présente à tous les niveaux de l'échelle sociale, avait davantage accès à la ville, à l'instruction, à la richesse, au prestige et au pouvoir que les Acadiens.

Comme les Maritimes avaient été fortement marquées par une vigoureuse immigration venue de la Nouvelle-Angleterre et d'Europe, les profils démographiques des anglophones varièrent en fonction de ces deux apports. Il est certain, par exemple, que le comportement des colons d'origine américaine s'apparenta davantage à celui des habitants de la NouvelleAngleterre qu'à celui des Acadiens. À cette différence près que les Maritimiens anglophones protestants ne semblent pas avoir adopté aussi vite que leurs voisins de la Nouvelle-Angleterre la solution du contrôle volontaire des naissances.

Lorsque se dessine après 1850 le mouvement d'urbanisation, de nouvelles différences entre les Acadiens et les anglophones s'ajoutèrent. Car, jusque-là, la population des deux groupes avait augmenté à un 
rythme rapide et sensiblement égal. Néanmoins, après 1860, les Acadiens doublèrent leurs effectifs en 40 ans, alors qu'il fallut un demi-siècle aux autres pour réaliser un maigre gain de $30 \%$. Au NouveauBrunswick, où ils se regroupaient de plus en plus, les Acadiens doublèrent leurs effectifs en 33 ans, pendant que les anglophones de la Nouvelle-Écosse accomplissaient le même geste en 60 ans. Pourtant, après 1881, au Nouveau-Brunswick et sur l'île-duPrince-Edouard, on assista même à un déclin numérique des anglophones. Il va sans dire que les taux de natalité et de mortalité, comme ceux d'urbanisation, fluctuèrent d'une province à l'autre aussi bien chez les Acadiens que chez les anglophones, sans pour autant se rejoindre. Il en fut ainsi à l'intérieur de chacune des provinces où les taux d'urbanisation, ainsi que ceux de natalité et de mortalité, furent différents dans les comtés dits acadiens et dans les autres. Tout cela est-il bien différent des polarisations observées au Québec?

Ceci dit, on ne saurait se surprendre si, dans les provinces atlantiques, les écarts de fécondité entre francophones et anglophones furent, pendant longtemps, plus faibles qu'ailleurs. Car, selon le recensement de 1961, ces disparités entre francophones et anglophones, chez les femmes de la région atlantique, déjà mariées et nées avant 1896, étaient encore de $37 \%$ parmi celles d'origine urbaine et rurale agricole, alors qu'elles étaient de $50 \%$ au Québec et en Ontario. C'est également dans ces provinces que le déclin de la fécondité fut, au $\mathrm{XX}^{\mathrm{e}}$ siècle, le plus rapide chez les femmes francophones mariées, nées en ville, et le plus lent chez celles nées sur des fermes comparées aux Québécoises et Ontariennes anglophones. 
Même si la démographie de l'Ontario fut sujette aux mêmes forces à long terme que le Québec et les Maritimes, elle ressembla plutôt, dans un premier temps, à celle des Maritimes qu'à celle du Québec. En effet, pendant la phase initiale de sa formation, cette portion du territoire québécois, depuis toujours vouée à la traite des pelleteries sous l'égide de Montréal, s'ouvrit à la colonisation agricole grâce à l'immigration. C'est d'ailleurs en réponse à la première immigration loyaliste que l'Angleterre érigea, entre 1783 et 1791 , des colonies séparées à même les territoires de la Nouvelle-Écosse et du Québec. Cette première vague loyaliste, constituée plus de familles que de célibataires, et plus de fermiers, d'artisans et de journaliers que de gens d'élite, fut suivie d'une seconde vague de même composition, qui accentua les progrès de l'agriculture, du commerce et des petites industries. La troisième vague, de caractère encore plus massif, également diversifiée socialement et formée surtout de familles, était avant tout originaire des Îles Britanniques. Devenu une colonie séparée, dépendante de la Grande-Bretagne et, à maints égards, du Bas-Canada, le Haut-Canada eut alors une croissance démographique et économique spectaculaire. Aussi gagna-t-il du terrain sur le Bas-Canada, au point qu'en 1850, tout en l'égalant presque en densité urbaine, il le surpassait en population, en production agricole et en activité industrielle.

Ainsi, en 1850, au moment où s'engage la première étape de l'urbanisation et de l'industrialisation, la société ontarienne était déjà diversifiée sur les plans ethnique, religieux, économique et social. Contrairement au Québec, les catholiques y étaient fortement minoritaires et les effectifs d'origine française étaient marginaux à tous égards. Comme les 
gens nés dans la colonie y représentaient alors 54\% de la population, alors qu'au Canada-Est ce pourcentage se situait à $90 \%$, on peut quand même dire, étant donné que le Canada-Ouest avait acquis une complexité sociale à peu près égale à l'autre, qu'il avait atteint une grande stabilité démographique et gagné substantiellement en maturité sociale.

On peut donc assumer que le comportement démographique originel des pionniers ontariens était similaire à celui des habitants de la Nouvelle-Angleterre, leur lieu d'origine, où une fraction importante d'entre eux commençait à se familialiser avec l'idée du contrôle des naissances. Lorsque le recrutement se déplaça vers les Îles Britanniques et que les colons de diverses origines s'adaptèrent à leur façon aux circonstances du pays, le niveau de la natalité s'abaissa aussi à des degrés variables d'un groupe ethnique ou religieux à l'autre sous l'effet du contrôle volontaire des naissances. Ainsi, selon David Gagan, le taux de fécondité des femmes du comté de Peel, qui était de 9 enfants en moyenne chez celles dont le mari n'était pas né au Canada, tomba successivement à $7,8 \mathrm{chez}$ celles qui s'étaient mariées à la fin des années 1840 à un âge se situant entre $20-24$ ans et à 6,8 en moyenne chez les femmes de la seconde et troisième générations. En somme, une évolution contraire à celle des premières générations de femmes de la Nouvelle-France et, après 1836, du Saguenay.

Cette baisse structurelle de la fécondité consécutive à la migration, reflet d'un changement de mentalité fleurissant plus volontiers dans les villes que dans les campagnes et en milieu protestant qu'en environnement catholique, était donc un phénomène durable stimulé par la croissance rapide de la population 
urbaine et par l'amélioration des niveaux d'éducation. En effet, de 1851 à 1911, la population urbaine anglophone de l'Ontario se multiplia 9,27 fois, alors que les effectifs ruraux n'augmentèrent que de $50 \%$. Â ce sujet, Gagan fait observer qu'en 1861 il existait, dans ce même comté, un écart de $26 \%$ entre la fécondité urbaine et celle des campagnes. Ce genre de polarisation, aussi observée au Québec et dans les Maritimes, existait déjà, une décennie plus tôt, dans la plupart des agglomérations urbaines de l'Ontario, non seulement pour la natalité mais aussi pour la mortalité.

Toujours est-il, si on s'en remet aux recensements, qu'en 1850 la natalité et la mortalité générale et infantile étaient plus basses en Ontario qu'au Québec et dans les Maritimes. Quatre-vingts ans plus tard, la natalité et la mortalité avaient partout décliné, mais les écarts traditionnels, bien que réduits, étaient toujours présents. Bien plus, à l'intérieur de chacune de ces unités géographiques, les taux de natalité et de mortalité des non-francophones furent toujours inférieurs à ceux des francophones. C'est un phénomène que Marc Termote et Danielle Gauvreau, après bien d'autres spécialistes de la démographie québécoise du $\mathrm{XX}^{\mathrm{e}}$ siècle, qualifient de surfécondité et de surmortalité historiques du groupe français ${ }^{91}$.

Ce phénomène, déjà observé dans les Maritimes, s'est aussi propagé à l'ouest du Québec dès le moment où les francophones allèrent constituer leurs premières communautés dans le sud-ouest et le centre ontariens. Les migrants venus du Québec après 1830 préférèrent s'établir le plus près possible de leur province natale, de sorte qu'en 1850 la minorité

${ }^{91}$ Marc Termote et Danielle Gauvreau, op. cit., p. 78, 90. 
DÉMOGRAPHIE DES COMMUNAUTÉS FRANCOPHONES

canadienne-française ontarienne était également répartie entre l'Est de la province et les autres régions.

Par la suite, au moment où se produisit l'émigration en masse des Québécois francophones vers la Nouvelle-Angleterre, une forte proportion d'entre eux, attirée par les terres disponibles, se dirigea vers l'Ontario. En 1911, ils étaient plus de 600000 au premier endroit et plus de 200000 au second: leurs taux de croissance respectifs étaient de $4,76 \%$ et de $2,86 \%$ par an, contre seulement $1,36 \%$ pour la population ontarienne anglophone. Ce mouvement à l'ouest du Québec eut une telle vigueur que, à peu près partout, les effectifs de langue française, tout en étant fortement minoritaires, s'accrurent plus vite que ceux du reste de la population ontarienne.

Après 1850, au lieu de se disperser à travers toute la province, ce qu'ils firent en partie, ces immigrants se concentrèrent surtout dans l'est de l'Ontario et leurs enfants y persistèrent jusqu'au moment où le terroir donna des signes de saturation. Puis, attirés par les perspectives de développement du nord ontarien, créées par les chemins de fer qui facilitaient l'accès aux forêts, aux mines et à de nouveaux terroirs, les migrants francophones de l'intérieur et de l'extérieur empruntèrent de préférence cette route. Ainsi, en 1911, contrairement aux anglophones qui étaient fortement surreprésentés dans le sud-ouest et le centre de la province, les trois quarts d'entre eux s'étaient regroupés dans l'Est et le Nord. Bien plus, dans chacune des régions, ils étaient très largement concentrés dans un petit nombre de comtés: trois dans les régions les plus anglophones de la province et sept districts électoraux dans l'Est et le Nord. Dans 
deux comtés de l'Est, ils avaient même acquis un statut majoritaire. Pour l'essentiel, ils se recrutaient parmi les couples mariés, les fils de cultivateurs, d'artisans et les journaliers. Leur niveau d'instruction originel était celui de la population rurale québécoise à l'époque de la migration et, s'il s'améliora par la suite, leurs gains furent moins importants que ceux de la population en place.

De tout cela, il ne faudrait pas conclure qu'ils se taillèrent aisément une place sur des terres dans les campagnes. Car un pourcentage significatif d'entre eux fut obligé de se fixer, temporairement ou pour de bon, dans les villages ou en ville. Ainsi, par la force des choses ou par choix, ils participèrent à leur façon au mouvement général d'urbanisation. Entre 1851 et 1911 , leur taux de croissance dans les villages et villes de 1000 habitants et plus fut de $5,13 \%$ en moyenne par an, contre 3,50\% pour les anglophones. Jusqu'en 1871, ils furent même plus urbains que les anglophones. En 1911, ceux-ci avaient une avance de $7 \%$ sur eux. Comme ils étaient surtout regroupés dans l'Est et le Nord, ils l'étaient, par le fait même, dans les régions où la terre était moins riche et les conditions moins propices au développement à long terme des villes et de l'industrie manufacturière. L'Est fut le seul endroit où leurs taux d'urbanisation furent toujours supérieurs à ceux des anglophones. De là, l'importance d'Ottawa, où leur proportion dans la population augmenta de $27 \%$ en 1851 à $30 \%$ en 1911. Pour eux, cette ville fut vraiment un centre de diversité sociale, de foisonnement des élites religieuses et laïques et des activités culturelles.

Ainsi, dans les villes comme dans les campagnes, les Franco-Ontariens constituaient une société diver- 
sifiée très dépendante à cette époque du Québec. Leurs dirigeants laïques urbains et ruraux en provenaient. Leurs élites cléricales anglophones et francophones se recrutaient dans le Québec, en Europe et, parfois, aux États-Unis, et elles appartenaient à la grande famille ultramontaine. À cet égard, mais à un plus fort degré, leur situation ressemblait à celle des Acadiens. Vers la fin du siècle, on peut dire que cette société commençait à trouver sa voie. Il n'en reste pas moins que, comme ailleurs, les francophones étaient surreprésentés dans les régions où le revenu agricole était moins élevé, où l'industrie manufacturière était la moins présente et les salaires moins hauts. Malgré les changements en cours, ils étaient partout, comme c'était le cas au Québec et dans les Maritimes, moins présents dans les activités professionnelles qui exigeaient un niveau d'éducation et de spécialisation plus considérable et qui, par conséquent, procuraient plus de richesse, de prestige et de pouvoir.

Il va sans dire que le profil démographique francoontarien reflétait la situation d'une population canadienne-française, catholique, moins alphabétisée que le reste de la population, en voie d'urbanisation et surreprésentée dans les catégories sociales plus susceptibles de favoriser la haute natalité et plus vulnérables à la maladie et à la mort. Cela explique certainement le fait que la natalité et, plus souvent qu'autrement, la mortalité générale et infantile aient été plus hautes dans les endroits où ils étaient les plus agglomérés que dans ceux où les anglophones dominaient fortement. Les recensements d'avant 1931 confirment, constamment en ce qui concerne la natalité et généralement dans le cas des mortalités, l'existence de ces disparités. 
En fait, il y eut des changements à cet égard puisqu'à leur arrivée, les immigrants francophones eurent un comportement qui était celui des régions du Québec d'où ils étaient originaires. Avec le temps, cependant, peut-être parce qu'ils furent toujours plus urbanisés que les Québécois francophones et qu'ils bénéficièrent des mesures de santé publique de l'Ontario, leur natalité et leur mortalité se démarquèrent jusqu'à un certain point de celles des Québécois francophones.

Peut-être aussi qu'ils devancèrent les Québécois francophones et les Acadiens dans le mouvement qui appelait le contrôle des naissances. Ce qui est clair, en tout cas, c'est que la fécondité des Québécoises francophones déjà mariées en 1961 et nées avant 1916 était supérieure à celle des Ontariennes, alors que celle des Ontariennes francophones était plus élevée que celle des Ontariennes du même âge.

\section{TABLEAU 23}

Nombre d'enfants nés vivants en plus par femme déjà mariée en 1961 (1) chez les Québécoises francophones que chez les Ontariennes et (2) chez les Ontariennes francophones que chez les Ontariennes

\begin{tabular}{lcccc}
\hline femmes nées & \multicolumn{2}{c}{$(1)$} & \multicolumn{2}{c}{$(2)$} \\
& villes & campagnes & villes & campagnes \\
avant 1896 & 2,81 & 3,90 & 2,10 & 2,70 \\
$1897-1901$ & 2,23 & 3,78 & 1,70 & 2,70 \\
$1902-1906$ & 1,82 & 3,59 & 1,40 & 2,32 \\
$1907-1911$ & 1,46 & 3,22 & 1,16 & 1,89 \\
$1912-1916$ & 1,91 & 2,92 & 0,94 & 1,81 \\
\hline
\end{tabular}

Source: Recensement du Canada, 1961.

Il résulte de tout ceci que les structures démographiques, celles qui expriment le plus spontanément le besoin naturel de se reproduire, de survivre et de se réaliser, se constituent et se transforment dans 
une constante interaction avec l'ethnicité, la religion, la culture, les besoins de la famille, le rapport à la ville, les niveaux d'instruction, la socioéconomie et les aspirations individuelles. Toutes ces forces, qui sont une création de l'histoire, contribuent de toutes sortes de façons, tantôt jouant de concert, tantôt en opposition, à confirmer ou à remettre en question les structures existantes. S'il est vrai que chacun de ces facteurs agissait depuis le XVII ${ }^{e}$ siècle, mais à des degrés variables selon les groupes, les lieux et les temps, sur les comportements démographiques, comment peut-on affirmer qu'avant 1850 la démographie était naturelle? Le fut-elle moins par la suite, à l'époque où s'affrontèrent les défenseurs du collectif religieux et national et les tenants de la liberté de choix de l'individu et de la qualité de la vie? 